\title{
Short and long-term effects of a synbiotic on clinical signs, the fecal microbiome, and metabolomic profiles in healthy research cats receiving clindamycin: A randomized, controlled trial
}

\author{
Jacqueline C Whittemore ${ }^{\text {Corresp.. }}{ }^{1}$, Jennifer E Stokes ${ }^{1}$ ， Nicole L Laia ${ }^{1}$ ， Joshua M Price ${ }^{2}$, Jan S Suchodolski ${ }^{3}$ \\ 1 Department of Small Animal Clinical Sciences, University of Tennessee - Knoxville, Knoxville, Tennessee, United States \\ 2 Office of Information Technology, University of Tennessee - Knoxville, Knoxville, Tennessee, United States \\ 3 The Gastrointestinal Laboratory, Small Animal Clinical Sciences, Texas A\&M University, College Station, TX, United States \\ Corresponding Author: Jacqueline C Whittemore \\ Email address: jwhittemore@utk.edu
}

Background. Antibiotic-associated gastrointestinal signs (AAGS) occur commonly in cats. Coadministration of synbiotics is associated with decreased AAGS in people, potentially due to stabilization of the fecal microbiome and metabolome. The purpose of this double-blinded randomized-controlled trial was to compare AAGS and the fecal microbiome and metabolome between healthy cats that received clindamycin with a placebo or synbiotic.

Methods. 16 healthy domestic shorthair cats from a research colony were randomized to receive 150 mg clindamycin with either a placebo (8 cats) or commercially-available synbiotic (8 cats) once daily for 21 days with reevaluation 603 days thereafter. All cats ate the same diet. Food consumption, vomiting, and fecal score were recorded. Fecal samples were collected daily on the last 3 days of baseline (days 57), treatment (26-28), and recovery (631-633). Sequencing of 16S rRNA genes and gas chromatography time-of-flight mass spectrometry was performed. Clinical signs, alpha and beta diversity metrics, dysbiosis indices, proportions of bacteria groups, and metabolite profiles were compared between treatment groups using repeated measures ANOVAs. Fecal metabolite pathway analysis was performed. $P<0.05$ was considered significant. The Benjamini \& Hochberg's False Discovery Rate was used to adjust for multiple comparisons.

Results. Median age was 6 and 5 years, respectively, for cats in the placebo and synbiotic groups. Hyporexia, vomiting, diarrhea, or some combination therein were induced in all cats. Though vomiting was less in cats receiving a synbiotic, the difference was not statistically significant. Bacterial diversity decreased significantly on days 26-28 in both treatment groups. Decreases in Actinobacteria (Bifidobacterium, Collinsella, Slackia), Bacteriodetes (Bacteroides), Lachnospiraceae (Blautia, Coprococcus, Roseburia), Ruminococcaceae (Faecilobacterium, Ruminococcus), and Erysipelotrichaceae (Bulleidia, [Eubacterium]) and increases in Clostridiaceae (Clostridium) and Proteobacteria (Aeromonadales, Enterobacteriaceae) occurred in both treatment groups, with incomplete normalization by days 631-633. Derangements in short-chain fatty acid, bile acid, indole, sphingolipid, benzoic acid, cinnaminic acid, and polyamine profiles also occurred, some of which persisted through the terminal sampling timepoint and differed between treatment groups.

Discussion. Cats administered clindamycin commonly develop AAGS, as well as short- and long-term dysbiosis and alterations in fecal metabolites. Despite a lack of differences in clinical signs between treatment groups, significant differences in their fecal metabolomic profiles were identified. Further 
investigation is warranted to determine whether antibiotic-induced dysbiosis is associated with an increased risk of future AAGS or metabolic diseases in cats and whether synbiotic administration ameliorates this risk. 
1 Short and long-term effects of a synbiotic on clinical signs, the fecal microbiome, and

2 metabolomic profiles in healthy research cats receiving clindamycin: a randomized,

3 controlled trial

4

5 Jacqueline C. Whittemore, ${ }^{1}$ DVM, PhD, DACVIM; Jennifer E. Stokes, ${ }^{1}$ DVM, DACVIM;

6 Nicole L. Laia, ${ }^{1}$ DVM; Joshua M. Price, ${ }^{2}$ MS; Jan S. Suchodolski, ${ }^{3}$ DrVetMed, PhD, AGAF, 7 DACVM.

8

$9{ }^{1}$ Small Animal Clinical Sciences, University of Tennessee, College of Veterinary Medicine,

102407 River Drive, Knoxville TN 37996

11

$12{ }^{2}$ Office of Information Technology, University of Tennessee, Knoxville, Knoxville TN 37996

13

$14{ }^{3}$ The Gastrointestinal Laboratory, Small Animal Clinical Sciences, Texas A\&M University,

15 College Station, TX 77843

16

17 Corresponding Author:

18 Jacqueline Whittemore

19 Email address: jwhittemore@utk.edu

20

21 
22 Background. Antibiotic-associated gastrointestinal signs (AAGS) occur commonly in cats. Co-

23 administration of synbiotics is associated with decreased AAGS in people, potentially due to

24 stabilization of the fecal microbiome and metabolome. The purpose of this double-blinded

25 randomized-controlled trial was to compare AAGS and the fecal microbiome and metabolome

26 between healthy cats that received clindamycin with a placebo or synbiotic.

27 Methods. 16 healthy domestic shorthair cats from a research colony were randomized to receive

$28150 \mathrm{mg}$ clindamycin with either a placebo (8 cats) or commercially-available synbiotic (8 cats)

29 once daily for 21 days with reevaluation 603 days thereafter. All cats ate the same diet. Food

30 consumption, vomiting, and fecal score were recorded. Fecal samples were collected daily on the

31 last 3 days of baseline (days 5-7), treatment (26-28), and recovery (631-633). Sequencing of $16 \mathrm{~S}$

32 rRNA genes and gas chromatography time-of-flight mass spectrometry was performed. Clinical

33 signs, alpha and beta diversity metrics, dysbiosis indices, proportions of bacteria groups, and

34 metabolite profiles were compared between treatment groups using repeated measures

35 ANOVAs. Fecal metabolite pathway analysis was performed. $P<0.05$ was considered significant.

36 The Benjamini \& Hochberg's False Discovery Rate was used to adjust for multiple comparisons.

37 Results. Median age was 6 and 5 years, respectively, for cats in the placebo and synbiotic

38 groups. Hyporexia, vomiting, diarrhea, or some combination therein were induced in all cats.

39 Though vomiting was less in cats receiving a synbiotic, the difference was not statistically

40 significant. Bacterial diversity decreased significantly on days 26-28 in both treatment groups.

41 Decreases in Actinobacteria (Bifidobacterium, Collinsella, Slackia), Bacteriodetes (Bacteroides),

42 Lachnospiraceae (Blautia, Coprococcus, Roseburia), Ruminococcaceae (Faecilobacterium,

43 Ruminococcus), and Erysipelotrichaceae (Bulleidia, [Eubacterium]) and increases in

44 Clostridiaceae (Clostridium) and Proteobacteria (Aeromonadales, Enterobacteriaceae) occurred 
45 in both treatment groups, with incomplete normalization by days 631-633. Derangements in

46 short-chain fatty acid, bile acid, indole, sphingolipid, benzoic acid, cinnaminic acid, and

47 polyamine profiles also occurred, some of which persisted through the terminal sampling

48 timepoint and differed between treatment groups.

49 Discussion. Cats administered clindamycin commonly develop AAGS, as well as short- and

50 long-term dysbiosis and alterations in fecal metabolites. Despite a lack of differences in clinical

51 signs between treatment groups, significant differences in their fecal metabolomic profiles were

52 identified. Further investigation is warranted to determine whether antibiotic-induced dysbiosis

53 is associated with an increased risk of future AAGS or metabolic diseases in cats and whether

54 synbiotic administration ameliorates this risk.

55

56 Introduction

57 Antibiotic administration is associated with profound, and sometimes prolonged, 58 derangements of the fecal microbiome and metabolome of people and animals (de La Cochetière 59 et al. 2010; Dethlefsen et al. 2008; Jakobsson et al. 2010; Suchodolski 2016b; Suchodolski et al. 60 2009). This dysbiosis is believed to be a primary contributor to the development of antibiotic61 associated gastrointestinal signs (AAGS), such as hyporexia, vomiting, and diarrhea (Hempel et 62 al. 2012; McFarland 2008; Videlock \& Cremonini 2012). Susceptibility to AAGS and 63 derangements in the microbiome both increase with repeated antibiotic exposure (Ouwehand et 64 al. 2016).

65 Antibiotic-associated gastrointestinal signs occur commonly in cats (Albarellos \&

66 Landoni 2009; 1995; Hunter et al. 1995) and people (Hempel et al. 2012; Lenoir-Wijnkoop et al. 67 2014; McFarland 2008), and they are an important cause of antibiotic non-compliance (Chan et 
68 al. 2012; Jefferds et al. 2002; Kardas et al. 2005; Llor et al. 2013; Muñoz et al. 2014; Pechere et

69 al. 2007). Co-administration of probiotics or synbiotics (commercial mixtures of probiotics and

70 prebiotics) with antibiotics is associated with up to a 3-fold decrease in AAGS in people

71 (Hempel et al. 2012; Johnston et al. 2011; Lenoir-Wijnkoop et al. 2014; Narayan et al. 2010;

72 Selinger et al. 2013). Positive effects of probiotics on AAGS in people are postulated to result

73 from stabilization of the fecal microbiome and metabolome (Hempel et al. 2012; Ouwehand et

74 al. 2016).

75 The impact of synbiotics on AAGS and antibiotic-induced dysbiosis in cats is currently

76 unknown. However, the administration of 1 commercially-available multi-strain synbiotic ${ }^{\mathrm{b}}$

77 resulted in significantly improved fecal scores for $72 \%$ of cats with idiopathic chronic diarrhea

78 (Hart et al. 2012), suggesting potential efficacy for reducing gastrointestinal signs due to other

79 causes. Prevention or mitigation of AAGS could decrease noncompliance by clients and, thus,

80 patient morbidity. Even if direct clinical effects are not observed, synbiotic administration might

81 be warranted if it is found to decrease antibiotic-induced changes in the microbiome and

82 metabolome and, thus, potentially reduce cumulative long-term sensitivity to AAGS and/or

83 metabolic disorders associated with antibiotic exposure, such as inflammatory bowel disease and

84 obesity (Aniwan et al. 2018; Kronman et al. 2012; Ouwehand et al. 2016).

85 The purpose of this study was to compare changes in food intake, vomiting, fecal scores,

86 the fecal microbiome, and the fecal metabolome of healthy cats receiving either a placebo or a

87 commercially-available synbiotic ${ }^{\mathrm{b}}$ with $150 \mathrm{mg}$ clindamycin orally once daily for 21 days. A

88 secondary objective of the study was to assess the long-term impacts of antibiotic and synbiotic

89 administration on the fecal microbiome and untargeted metabolomic profiles of healthy cats. 


\section{$91 \quad$ Materials and Methods}

92 Study population: This study was performed at the University of Tennessee's Veterinary Medical

93 Center and was approved by the Institutional Animal Care and Use Committee at the University

94 of Tennessee, Knoxville (protocol number 2169). Twenty purpose-bred, domestic short hair

95 research cats from the University of Tennessee, College of Veterinary Medicine teaching and

96 research colony determined to be healthy based on unremarkable physical examinations at the

97 time of study initiation and lack of pertinent abnormalities on CBC or biochemistry profiles

98 performed within the previous 6 months were enrolled. Prior antibiotic use was not noted in any

99 of the medical records. All cats ate the same commercial adult dry cat food for the duration of

100 the study. ${ }^{\mathrm{c}}$ Cats were transitioned to individual housing the week prior to the start of the study

101 and randomized into 1 of 2 treatment groups (placebo vs. synbiotic) at the start of the study using

102 a random number sequence.

103 Study periods: The study consisted of a baseline period (days 1-7), a treatment period (days 8-

104 28), and a long-term follow-up period (days 631-633) (Figure 1). During the baseline period, no

105 treatments were administered. During the treatment period, all cats received $150 \mathrm{mg}$ (34

$106 \mathrm{mg} / \mathrm{kg} / \mathrm{d}$, range $25.9-44.1 \mathrm{mg} / \mathrm{kg} / \mathrm{d}$ ) of clindamycin ${ }^{\mathrm{d}} \mathrm{PO}$ once daily with food for 21 days. The

107 dose was chosen based on the manufacturer drug insert, ${ }^{\mathrm{a}}$ which noted changes in fecal

108 consistency and emesis in cats receiving higher doses of clindamycin. At the time of antibiotic

109 administration, cats received either 1 capsule of placebo or a commercially-available synbiotic ${ }^{b}$

110 PO once daily at the time of antibiotic administration. The synbiotic contains 5 billion $c f u$ of a

111 proprietary mixture of Bifidobacterium bifidum, Enterococcus faecium and thermophilus, and

112 Lactobacillus acidophilus, bulgaricus, casei, and lantarum per capsule, as well a proprietary

113 blend of fructooligosaccharide and arabinogalactan. The time period for treatment was chosen 
114 based on previous veterinary publications (Garcia-Mazcorro et al. 2011; Hart et al. 2012;

115 Koeppel et al. 2006), which showed significant changes in the fecal microbiome or fecal score

116 by 21 days of treatment. After completion of treatment, cats were returned to group housing in

117 the colony. On day 631, cats remaining in the teaching and research pool were reevaluated.

118 Based on review of their medical records, none of the cats had received antibiotics, probiotics,

119 other medications known to affect the microbiome, or dietary change in the intervening time.

120 Data collection: All cats underwent weekly physical examinations, including determination of

121 body weight, throughout the study. Daily observations, including food intake and vomiting

122 (present vs. absent), were collected throughout the study by an observer blinded to the treatment

123 groups. Photographs of defecated feces were taken daily by the same observer. Fecal consistency

124 was scored (Greco 2011) using still photographs at the completion of data collection by 2

125 investigators (JCW and JES), who were blinded to the cat, treatment group, and day for each

126 fecal sample.

127 Fecal samples: To limit the impact of daily variation in bacterial populations and fecal

128 metabolites, as well as differential distribution of bacterial groups and metabolites within

129 individual fecal samples, first morning naturally-voided fecal samples were collected daily for 3

130 days for each cat at each of 3 timepoints: the conclusion of baseline (days 5-7), the conclusion of

131 treatment (days 26-28), and after long-term recovery (days 631-633). 2 grams from the center

132 portion of each fecal sample was subdivided into 2 aliquots, with each aliquot placed into a $2 \mathrm{~mL}$

133 cryovial. Samples were immediately frozen and remained in storage at $-80^{\circ} \mathrm{C}$ pending completion

134 of data collection. Samples for each cat from each timepoint were combined directly prior to

135 sample analysis to generate pooled samples for microbiome and metabolomic analysis.

136 Microbiome analysis: Genomic DNA was extracted from $100 \mathrm{mg}$ of feces from each pooled 
137 sample using a commercially available kit according to manufacturer's protocol. ${ }^{\mathrm{e}}$

138

139

140

141

142

143

144

145

146

147

148

149

150

151

152

153

154 155

157 158 159

Amplification and sequencing of the V4 variable region (primers 515F/806R) of the $16 \mathrm{~S}$

rRNA gene was performed on a MiSeq (Illumina) ${ }^{\mathrm{f}}$ as previously described (Bell et al. 2014). The software Quantitative Insights Into Microbial Ecology (QIIME, v. 1.8) ${ }^{\mathrm{g}}$ was used for processing and analyzing the sequences. The raw sequence data were de-multiplexed, and low quality reads were filtered using default parameters for QIIME. Chimeric sequences were filtered from the reads using USEARCH against the 97\% clustered representative sequences from the Greengenes database (v. 13.8) and removed. The remaining sequences were assigned to operational taxonomic units (OTUs) using an open-reference OTU picking protocol using the default QIIME parameters, uclust consensus taxonomy assigner, and Greengenes database. The OTU table was rarefied to 35,000 sequences per sample. Alpha rarefaction plots, alpha diversity metrics (Chao1, Shannon, Goods Coverage, and Observed Species), and beta diversity metrics (weighted and unweighted UniFrac distance matrices) were created using QIIME scripts.

Quantitative PCR was performed for selected bacterial groups (total bacterial,

Faecalibacterium spp., Turicibacter spp., Streptococcus spp., Escherichia coli, Blautia spp.,

Fusobacterium spp., Clostridium hiranonis) using extracted DNA as has been previously described (AlShawaqfeh et al. 2017). Briefly, $2 \mu 1$ of normalized DNA (final concentration: 5 $\mathrm{ng} / \mu \mathrm{l})$ was combined with $5 \mu \mathrm{l}$ of a DNA-binding dye, ${ }^{\mathrm{h}} 0.4 \mu \mathrm{l}$ each of a forward and reverse primer (final concentration: $400 \mathrm{nM}$ ), and $2.6 \mu \mathrm{l}$ of PCR water to achieve a total reaction volume of $10 \mu \mathrm{l}$. Oligonucleotide primers and probes, as well as respective annealing temperatures, are summarized in Table 1. Data were expressed as log amount of DNA (fg) for each particular bacterial group per $10 \mathrm{ng}$ of isolated total DNA. 
160 Metabolomics analysis: $10 \mathrm{mg}$ of lyophilized feces from each pooled sample were analyzed at a

161 metabolomics facility ${ }^{\mathrm{h}}$ using gas chromatography time-of-flight mass spectrometry (GC-TOF-

162 MS) and standardized protocols as described in detail elsewhere (Fiehn et al. 2008; Minamoto et

163 al. 2015). Raw data files were processed using ChromaTOF v. 2.32. BinBase algorithm was

164 applied to match spectra to database compounds ${ }^{\mathrm{i}}$ or to characterize as an unknown compound as

165 reported previously (Honneffer et al. 2017). Quantification was reported by peak height of an ion

166 at the specific retention index characteristic of the compound across all samples.

167 Statistical analyses: Descriptive statistics were generated for each parameter. Samples were

168 analyzed for normality using the Shapiro-Wilk test and, for the presence of outliers, using box-

169 and-whisker plots. Age and weight for the 2 treatment groups were compared using an

170 independent two-sample Student's t-test. Mean percent food intake, percent days of vomiting,

171 and mean fecal scores were determined for each week within each study period (baseline and

172 treatment weeks 1, 2, and 3). Mean food intake for each week in each study period was

173 calculated as a percentage of food intake of each cat during the week prior to the start of the

174 study. Inter-rater correlation coefficients were calculated for fecal scores. The mean of fecal

175 scores assigned by the 2 investigators were used for all further statistical analyses. Mean food

176 intake, percent days vomiting per week, and mean fecal score were compared between treatment

177 groups using a multivariate repeated measures ANOVA. Treatment group (placebo or synbiotic),

178 week, and cat were included as categorical variables. Treatment, week, and the treatment-by-

179 week interaction were included as fixed effects. Week was included as a repeated measure with

180 subject as cat. Age, sex, and weight were initially included as covariates but were not retained in

181 the final models. Model assumptions regarding normally distributed residuals were verified with

182 the Shapiro-Wilk test for normality. Model assumptions regarding equality of variances were 
183 verified with Levene's Test for Equality of Variances.

184 Global changes in microbiota communities (beta diversity) between individuals were

185 determined using unweighted Unifrac distance metrics; principal coordinates analysis (PCoA)

186 plots and rarefaction curves were plotted using QIIME software. The ANOSIM function in

187 PRIMER $6^{\mathrm{j}}$ was used to compare beta diversity metrics across time and between treatment

188 groups (Suchodolski et al. 2012). A dysbiosis index was calculated through methods previously

189 described (AlShawaqfeh et al. 2017). The dysbiosis index is a quantitative PCR-based assay that

190 summarizes the quantitative abundances of 8 major bacterial groups in feces in 1 number. The

191 higher the dysbiosis index, the more deviation of the microbiota from normobiosis. Global

192 changes in untargeted metabolomic profiles were determined using principal component analysis

193 (PCA) plots developed using an online metabolomics software analysis suite ${ }^{\mathrm{k}}$ as per standard

194 protocols (Xia et al. 2015; Xia \& Wishart 2011). Pathway analysis was performed in the same

195 software suite using the Homo sapiens pathway library, interquantile range data filtering, log

196 transformation, and Pareto scaling.

197 Shannon indices, goods coverage, the Chao 1 metric, the dysbiosis index, proportions of

198 bacteria groups, and fecal metabolite profiles were compared between treatment groups using a

199 mixed model, split-plot repeated measures ANOVA that included fixed effects of treatment

200 (placebo or synbiotic), time period, and treatment-by-time period interaction. Cat nested within

201 group was included as a random effect. Age and sex were included as covariates in the initial

202 analysis, but they were not retained in the final model due to lack of significant effects. The

203 repeated measure of time period was accounted for in a repeated statement. A compound

204 symmetry variance/covariance structure was incorporated into each model to account for the

205 potential inclusion of constant covariates over time. The Shapiro-Wilk test of normality of the 
206 residuals was evaluated for each marker to confirm the assumption of normally distributed

207 residuals had been met. Model assumptions regarding equality of variances were verified with

208 Levene's Test for Equality of Variances. Differences in least squares means were determined for

209 markers with significant main effect or interaction terms. Due to a marked lack of variability in

210 microbiome results for cats on days 26-28 (see Results below), rank transformation had to be

211 employed to allow convergence of the model for analysis of the proportions of bacteria groups

212 and ensure the statistical assumptions regarding normally distributed residuals and equality of

213 variances were met. Only bacteria taxa that were present in at least $50 \%$ of cats in $\geq 1$ group at $\geq$

2141 time point were included in statistical analyses.

$215 P<0.05$ was considered statistically significant. $P$-values were corrected for multiple

216 comparisons on each phylogenetic level and for untargeted metabolomics using the Benjamini \&

217 Hochberg's False Discovery Rate (fdr). Publicly-accessible software packages ${ }^{\mathrm{g}, \mathrm{k}-\mathrm{m}}$ were used for 218 all analyses.

219

\section{Results}

221 Study population: There were 4 female spayed and 6 male castrated cats in the placebo group

222 and 5 female spayed cats and 5 male castrated cats in the synbiotic group. Median age was 6

223 years (range 3-8 years) for cats in the placebo group and 5 years (range 3-8 years) for cats in the

224 synbiotic group. Median weight was $4.2 \mathrm{~kg}$ (range 3.4-5.4 kg) for cats in the placebo group and

$2254.3 \mathrm{~kg}(3.4-5.8 \mathrm{~kg})$ for cats in the synbiotic group. No cat vomited any of the administered

226 capsules during the study. Four cats were removed from the study for marked hyporexia (2

227 placebo, 1 synbiotic) or high baseline fecal scoring (1 synbiotic).

228 After completion of treatment, cats were returned to the colony. On day $631,15 / 16$ of the 
229 cats that completed the trial were available for re-examination. One cat (from the synbiotic

230 group) had been retired from the colony with subsequent private adoption. None of the cats had

231 received antibiotics, probiotics, or other medications known to affect the microbiome in the

232 intervening time, and none had undergone diet change. None of the cats were experiencing

233 vomiting, abnormal fecal scores, or inadequate body condition scores.

234 Antibiotic-associated gastrointestinal signs: Food intake, percent days vomiting, and fecal scores

235 over time by treatment group are summarized in Table 2. Food intake was decreased during

236 treatment in $3 / 8$ cats in the placebo group and $4 / 8$ cats treated with the synbiotic. Food intake

237 was significantly associated with week of treatment (F-value 5.2, $P<0.01$ ) but did not differ

238 between treatment groups $(P=0.5)$. Percent days vomiting per week was significantly associated

239 with week of treatment (F-value 8.6, $P<0.01$ ) but not treatment group $(P=0.4)$. It was highest

240 in the first week of treatment, during which 14/16 cats had at least 1 episode of vomiting, 7 in

241 each group. Fecal scores increased significantly during treatment (F-value 9.4, $P<0.01$ ) but did

242 not differ between treatment groups $(P=0.2)$. All cats in each treatment group had fecal scores $\geq$

2435 at some point during treatment, although high daily variability was noted. There was no

244 significant effect of age, weight, or sex on any of the clinical parameters evaluated.

245 Fecal microbiome: Cats in both treatment groups had marked changes in their fecal microbiome

246 over time (Figures 2-3). Alpha diversity was significantly lower $(P<0.01)$ on days $26-28$, based

247 on the Shannon index, goods coverage, and Chaol metric (Table 3). There was no significant

248 association between treatment group and changes in Shannon index, goods coverage, or the

249 Chaol metric. Similarly, beta diversity was significantly altered on days $26-28$ compared to

250 baseline and days 631-633 in each treatment group $(P<0.01 ; \mathrm{R}=0.73-0.76)$ with no significant

251 differences between treatment groups (Figure 2). The dysbiosis index was significantly higher on 
252 days 26-28 than at baseline or on days 631-633 in each treatment group (Table 3), and a

253 significant association was found between treatment group and dysbiosis index (Table 3, F-value

254 13.6, $P<0.01)$.

255 Five phyla were identified based on sequencing analysis (mean baseline prevalences):

256 Actinobacteria (67.95\%), Firmicutes (30.39\%), Proteobacteria (1.03\%), Bacteroidetes (0.73\%),

257 and Fusobacteria $(0.02 \%)$, with marked and significant differences over time in relative

258 abundances of all phyla except Fusobacteria (Figure 3, Table 4). There was no significant effect

259 of treatment group on changes in relative bacterial abundances at any timepoint, and there was

260 no significant association between age or sex and changes in any of the analyzed fecal

261 microbiome parameters.

262 Metabolome: Untargeted fecal metabolomics profiles differed markedly over time for cats in 263 both treatment groups (Figures 4-5), with a variety of patterns of changes found. Fecal profiles

264 for 178 of 252 assayed compounds (71\%) differed significantly over time (see Additional file 1).

265 Of those that differed over time, 47 of 178 (26.4\%) metabolites had equivalent profiles at

266 baseline and days 631-633. Partial return to baseline profiles were identified for an additional 14

267 metabolites (7.9\%), and 21 metabolites (11.8\%) had altered profiles on days $26-28$ compared to

268 baseline with no significant changes between days 26-28 and days 631-633. Changes in profiles

269 for the remaining 96 metabolites (53.9\%) were more complex. Profiles for 33 compounds

270 (18.5\%) differed significantly on days 631-633 from both baseline and days 26-28 with no

271 difference between baseline and days 26-28, and profiles for 14 metabolites (7.9\%) were

272 significantly higher or lower at days $26-28$ compared to baseline with further significant changes

273 in the same direction by days 631-633. In contrast, profiles for 30 metabolites (16.9\%) were

274 significantly higher at days 26-28 than baseline but also significantly lower at days 631-633 than 
275 baseline; profiles for another 14 metabolites (7.9\%) were decreased on days 26-28 with much

276 higher profiles on days 631-633 than baseline. Finally, 5 metabolites had individual patterns of 277 change.

$278 \quad$ Significant differences (fdr adjusted $P<0.05$ ) were noted between treatment groups for 7

279 metabolite profiles (Figure 6). Significant group by time interactions were found for fecal 280 profiles of putrescine, isopentadecanoic acid, cellobiose, ethanolamine, lactose, and D-erythro281 sphingosine, while fecal profiles for $\mathrm{N}$-acetylglutamate differed significantly by treatment group 282 alone.

283 With regard to metabolites of known biological importance, there were significant 284 changes in profiles of some short-chain fatty acid (SCFA) synthesis metabolites, bile acids, 285 tryptophan degradation pathway metabolites, sphingolipids, polyamines, and benzoic and 286 cinnaminic acids over time (Table 5). Pathway analysis revealed significant changes (fdr 287 adjusted $P<0.05$ ) over time for 55 metabolic pathways; 47 of which had impact factors $>0$ 288 (Table 6). The majority of pathways affected were related to SCFA, amino acid, sugar, and 289 nucleotide synthesis and degradation. Amino acid pathways that were affected included those 290 related to tryptophan degradation. Other pathways significantly affected included those related to 291 linoleic acid, sphingolipid, and glycerolipid metabolism.

293 Discussion

294 The incidence of AAGS varies in people based on individual antibiotic agent, prior 295 antibiotic exposure, subject age, and other factors (Hempel et al. 2012; Lenoir-Wijnkoop et al. 296 2014; McFarland 2008; Ouwehand et al. 2016). Antibiotics, such as clindamycin, can cause 297 AAGS directly by stimulating the intestinal motilin receptor (Bartlett 2002). However, 
298 antibiotic-induced dysbiosis, with secondary alterations in fecal metabolites and overgrowth of

299 opportunistic pathogens, is believed to be the primary contributor to AAGS (Gustafsson et al.

300 1998; McFarland 2008; Varughese et al. 2013; Videlock \& Cremonini 2012). Dysbiosis is

301 greatest for broad-spectrum and poorly-absorbed antibiotics, including macrolides,

302 cephalosporins, and fluoroquinolones (Jakobsson et al. 2010; Löfmark et al. 2006; McFarland

303 2008; Ouwehand et al. 2016), and alterations to the microbiome can persist at least 4 years after

304 short-term antibiotic therapy (Jakobsson et al. 2010; Löfmark et al. 2006).

305 Multiple metanalyses support the efficacy of probiotics in preventing AAGS in people

306 (Goldenberg et al. 2015; Lau \& Chamberlain 2016; McFarland 2016; Ouwehand et al. 2016;

307 Szajewska et al. 2016; Videlock \& Cremonini 2012). Although some gastrointestinal effects

308 appear to be dose-related (Ouwehand et al. 2016; Pagnini et al. 2010; Szajewska et al. 2016),

309 effects do not correlate directly with the relative abundances of probiotic bacteria or measurable

310 shifts in OTUs in the fecal microbiome (Biagi et al. 2013; Garcia-Mazcorro et al. 2011;

311 Marshall-Jones et al. 2006; Rossi et al. 2014). The ideal microbial strain(s), dose, and timing

312 relative to antibiotic administration likely vary by antibiotic, underlying disease processes,

313 patient (age, inpatient status, historical antibiotic exposure), and other factors (Lau \&

314 Chamberlain 2016; McFarland 2009; Szajewska et al. 2016). Positive effects of probiotics

315 include stimulation of the host's innate system and epithelial secretion of antimicrobial

316 substances, restoration of intestinal barrier function, alteration of the gastrointestinal

317 metabolome, disruption of biofilms through production of bacteriocins, generation of other

318 antimicrobial agents, and competitive exclusion of pathogens (Ohland \& MacNaughton 2010;

319 Ouwehand et al. 2016; Pagnini et al. 2010; Quigley 2012; Rossi et al. 2014; Strompfová et al.

320 2004). 
Although AAGS are a recognized complication of antibiotic therapy in cats (Albarellos \&

322 Landoni 2009; Bureau of Veterinary Drugs 1995; Hunter et al. 1995), the incidence of AAGS,

323 short- and long-term effects on the microbiome and metabolome, and impact of concurrent

324 synbiotic administration had not been previously characterized. In this study, AAGS developed

325 in $100 \%$ of cats treated with high dose clindamycin once daily for 21 days. Vomiting was most

326 severe in the first week of therapy, although it persisted for the duration of treatment in some

327 cats. A temporal association between antibiotic administration and vomiting was not noted,

328 suggesting stimulation of the motilin receptor by clindamycin had minimal impact on the

329 incidence of vomiting. The incidence of vomiting per week was less in cats receiving the

330 synbiotic, but the difference between treatment groups was not statistically significant. Fecal

331 consistency and food intake declined progressively throughout the course of treatment in both

332 treatment groups.

333 There are a number of potential explanations for the lack of statistically significant

334 differences in AAGS between treatment groups in this study. A high antibiotic dose was used to

335 increase the likelihood of detecting a difference between groups because the incidence of AAGS

336 due to clindamycin was unknown. Ironically, this might have obscured positive results due to the

337 severity of AAGS induced. The synbiotic dose chosen for the study was based on a prior report

338 describing clinical improvement in cats with chronic enteropathy treated with the same synbiotic

339 (Hart et al. 2012), but use of a higher dose might be required to prevent AAGS. We elected to

340 administer the synbiotic concomitantly with clindamycin because compliance with medication

341 regimens is inversely correlated with the number or frequency of treatments (Adams et al. 2005;

342 van den Bemt et al. 2016), primarily due to forgetfulness and/or logistical difficulties of

343 balancing treatment schedules against other daily responsibilities (Col et al. 1990). Although 
344 macrolide resistance occurs in a relatively high percentage of Enterococcus faecium and

345 Lactobacillus strains, as well as a Bifidobacterium animalis probiotic (European Food Safety

346 Authority 2012; Ouwehand et al. 2016; Strompfová et al. 2004), antibiotic sensitivity of the

347 bacterial strains in the study drug were not determined so neutralization due to concomitant

348 antibiotic administration cannot be ruled out.

349 To further assess the potential efficacy of synbiotics in preventing AAGS in cats, our

350 group has since performed a follow-up study (Stokes et al. 2017) using a crossover design with a

351 6-week washout period, a more clinically relevant clindamycin dose (mean $18 \mathrm{mg} / \mathrm{kg} / \mathrm{d})$, a higher

352 synbiotic dose (10 billion $c f u / d$ ), and delaying administration of the synbiotic for 1 hour after

353 antibiotic administration to limit potential synbiotic neutralization. Cats receiving the synbiotic

354 were significantly more likely to complete the initial treatment course, vomited less, and had

355 higher food intake than cats receiving the placebo. Interesting, strong period effects were noted -

356 suggesting ameliorative effects of synbiotics on AAGS may persist for at least 6 weeks after

357 administration. Because the antibiotic and synbiotic doses, as well as timing of synbiotic

358 administration, were all altered in that study, it is not possible to ascertain which factor had the

359 greatest impact on clinical signs.

360 In addition to causing AAGS, clindamycin administration was associated with marked

361 changes in the fecal microbiome and metabolome in this study. Alterations in alpha diversity

362 (Shannon index, Goods coverage, Chao1 metric), beta diversity, and the dysbiosis index returned

363 to baseline levels by the end of the washout period. The return of diversity at a global level was

364 not due to return to baseline abundances for individual OTUs. Instead, changes in relative

365 abundances of many individual OTUs persisted through the terminal sampling timepoint $(>600$

366 days after discontinuation of antibiotic therapy) in both treatment groups. Changes included 
367 reductions in the abundances of Actinobacteria, including Bifidobacterium, Collinsella, and

368 Slackia; Bacteroidetes, including Bacteroides; many members of the Clostridium clusters IV and

369 XIV, including Lachnospiraceae (Blautia, Coprococcus, and Roseburia), Ruminococcaceae

370 (Faecalibacterium and Ruminococcus), and Erysipelotrichaceae (Bulleidia and [Eubacterium]);

371 and Veillonellaceae, including Megamonas. Marked increases in abundance were identified for

372 Clostridiaceae, including Clostridium, and Proteobacteria, including Aeromonadales but

373 primarily due to increases in Enterobacteriaceae. Alterations were generally consistent with

374 those found in cats (Ramadan et al. 2014; Suchodolski et al. 2015) and people (Schubert et al.

375 2014) with dysbiosis due to naturally-occurring diarrhea. Interestingly, decreased relative

376 abundances of Lachnospiraceae and Ruminococcaceae also have been found in cats infected

377 with Giardia and feline immunodeficiency virus (Šlapeta et al. 2015; Weese et al. 2015).

$378 \quad$ Antibiotic-induced dysbiosis and gastrointestinal signs have been associated with

379 alterations in a variety of metabolite profiles. Consistent with prior work in people (Gustafsson et

380 al. 1998; McFarland 2008; Woodmansey et al. 2004), we found marked derangements in SCFA

381 profiles and pathways during antibiotic administration, some of which persisted at days 631-633.

382 No difference was found in SCFA profiles between treatment groups. In addition to being an

383 important energy source for colonocytes, SCFAs have anti-inflammatory and

384 immunomodulatory effects, regulate intestinal motility, and maintain intestinal barrier function

385 (Quigley 2012; Suchodolski 2016a). Persistent alterations in SCFA profiles could perpetuate

386 ongoing dysbiosis after resolution of the initial insult.

387

Decreased proportions of secondary bile acids, important for maintaining eubiosis and

388 modulating the immune system, have been found in people and dogs with gastrointestinal disease

389 (Duboc et al. 2013; Honneffer et al. 2015). Similarly, we identified a marked reduction in 
390 secondary versus primary bile acids during antibiotic administration, followed by an increase at 391 days 631-633 above baseline. It is possible, though speculative, that the inversion in the ratio of 392 primary to secondary bile acids on days 631-633 reflects a compensatory response to persistent, 393 occult dysbiosis and inflammation. Temporal alterations in bile acid biosynthesis were also noted 394 on pathway analysis but did not achieve significance (fdr adjusted $P=0.06$ ).

Indole profiles, the product of tryptophan degradation by commensal E. coli, have 396 previously been found to be decreased in people and animals with gastrointestinal disease 397 (Suchodolski 2016a). In this study, indole profiles decreased significantly during antibiotic 398 administration in both treatment groups. Indole profiles failed to return to baseline values by 399 days 631-633 for cats in the placebo group, while they were mixed for cats in the synbiotic 400 group. Direct effects of indole within the gut lumen include decreased production of adherence 401 and virulence factors, motility, biofilm formation, and adherence of pathogenic E. coli (Bansal et 402 al. 2007), while effects on the intestine include strengthening of intestinal tight junctions, 403 increased production of mucin to shield the epithelium from bacterial adherence, and modulation 404 of inflammation (Bansal et al. 2010). Persistent alterations in indole profiles in cats not 405 administered a synbiotic with antibiotics could contribute to a pro-inflammatory state, as well as chronically increased intestinal permeability and risk of bacterial colonization and translocation. Significant temporal changes also were found in profiles of D-erythrosphingosine, isopentadecanoic acid, and cellobiose. D-erythro-sphingosine is a sphingolipid,

409 while isopentadecanoic acid and cellobiose are components of sphingolipids and 410 sphingophospholipids (Chao et al. 1992; Minamino et al. 2003; Vesper et al. 1999).

411 Sphingolipids and sphingophospholipids have antineoplastic properties, stimulate the innate

412 immune system, and increase bacterial clearance (Chao et al. 1992; Fujiwara et al. 2013; 
413 Minamino et al. 2003). Persistent reductions in putrescine profiles in cats in the placebo, but not

414 the synbiotic, group after antibiotic exposure also were noted. Putrescine, along with spermine

415 and spermidine, are polyamines. Polyamine supplementation increases resistance to oxidative

416 stress in mice, while depletion is associated with development of pancreatitis (Minois et al.

417 2011). Further study will be necessary to determine the clinical relevance of differing

418 sphingolipid and putrescine profiles between treatment groups over time.

419 Finally, significant associations were found in profiles for cinnaminic acid and benzoic

420 acid compounds. Compounds in both treatment groups had lower results at days 26-28 than

421 baseline. Benzoic acid profiles were higher at days 631-633 than at baseline, while cinnaminic

422 profiles did not return to baseline levels. Both cinnaminic and benzoic acids have been found to

423 have antimicrobial effects, and cinnaminic acids have additional anti-inflammatory properties

424 (Alam et al. 2016; Manuja et al. 2013). The persistent decrease in cinnaminic acid profiles after

425 antibiotic administration is particularly intriguing given work in research models suggesting

426 potential benefits of cinnaminic acids in management of obesity and diabetes mellitus (Alam et

427 al. 2016). Repeated exposure to antibiotics has been associated with increased risks of childhood

428 obesity and diabetes mellitus (Mikkelsen et al. 2016; Scott et al. 2016). It is possible, though

429 certainly speculative at this juncture, that associations between antibiotic exposure and increased

430 risk of obesity and diabetes are at least partially due to cumulative derangements in cinnaminic

431 acid profiles.

432 One factor that could impact clinical application of these results is the use of healthy

433 research cats. Creation of AAGS in healthy privately-owned animals for antibiotic-related

434 investigations poses concerns regarding compliance with the study protocol, while evaluations in

435 clinically ill animals can be confounded by heterogeneity in underlying disease, the antibiotic 
436 required for the primary disease, prior antibiotic exposure, and husbandry factors. The

437 predominant phylum identified at baseline in this study, Actinobacteria, conflicted with that

438 found in recent reports in privately-owned healthy cats, Firmicutes (Bell et al. 2014; Suchodolski

439 et al. 2015; Weese et al. 2015), though they agree with findings of other studies, particularly

440 those using research colony cats (Abecia et al. 2010; Desai et al. 2009; Jia et al. 2011a; Jia et al.

441 2011b). Although Firmicutes was the predominant phyla in the first 3 studies (Bell et al. 2014;

442 Suchodolski et al. 2015; Weese et al. 2015), relative abundance ranged from 50-80\% with

443 similar variability in Actinobacteria (0.11-9.9\%), Bacteroidetes (0.15-33\%), Fusobacteria (0-

$444 \quad 1.15 \%)$ and Proteobacteria (0-30\%). Differences among studies also could reflect geographical

445 variation, heterogeneity in diet, or variable exposure to other treatments known to impact the

446 microbiome. Although cats in this study had not previously received antibiotics, probiotics or

447 proton-pump inhibitors, data on potential exposure to them were not included in the other

448 reports.

449 Because there was not a control group that received neither antibiotics nor probiotics, it is

450 not possible to definitively ascribe long-term changes in the fecal microbiome and metabolome

451 to antibiotic administration. Although the fecal microbiome of cats evolves with age,

452 predominant bacterial groups and relative abundances appear relatively stable in colony cats

453 based on evaluation of cats from 1 to 9 months of age and 8 to 14 years from the same colony

454 (Jia et al. 2011a; Jia et al. 2011b). Further, we did not identify an association between the age of

455 cats and the composition of the microbiome at baseline. As such, exposure to antibiotics is the

456 most likely cause for the marked changes in fecal microbiome and metabolomic profiles over

457 time. Interestingly, we also found no association between age and AAGS, in contrast to work in

458 people (McFarland 2008). 


\section{Conclusions}

High-dose clindamycin therapy induces AAGS in $100 \%$ of cats, and severity of signs is

462 often treatment-limiting. The incidence of vomiting was lower in cats concurrently administered

463 a synbiotic, although the difference was not statistically significant. Antibiotic-induced dysbiosis

464 and alterations in fecal metabolite profiles mirror those found in people. Changes in fecal

465 metabolomic profiles included derangements in SCFA, bile acid, indole, sphingolipid,

466 polyamine, benzoic acid, and cinnaminic acid metabolism. Changes in relative abundances of

467 many OTUs and metabolite profiles persisted for $>600$ days after treatment discontinuation.

468 Significant differences between synbiotic and placebo groups were noted for metabolites that

469 affect immunomodulation, intestinal permeability and barrier function, colonization resistance,

470 and oxidative stress. Further investigation is warranted to determine whether synbiotics blunt

471 AAGS or the risk of antibiotic-associated metabolic derangements, such as obesity, in cats

472 undergoing repeated antibiotic therapy.

473

\section{Footnotes}

475 aAntirobe ${ }^{\circledR} /$ Antirobe $^{\circledR}$ Aquadrops manufacturer insert, Pfizer Pharmacia, March 2010.

476 broviable- $D C^{\circledR}$, Nutramax Laboratories Veterinary Sciences, Inc., Lancaster, SC USA.

477 'Hill's ${ }^{\circledR}$ Science Diet ${ }^{\circledR}$ Light, Hill's Pet Nutrition, Inc., Topeka, KS USA.

478 dAntirobe ${ }^{\circledR} /$ Antirobe $^{\circledR}$ Aquadrops, Pfizer, Pharmacia \& Upjohn Company, New York, NY USA.

479 ePowerSoil®, Mo Bio, Carlsbad, CA USA.

480 fMR DNA (Molecular Research LP), Shallowater, TX USA.

481 gQIIME, v. 1.8. Available at: http://www.qiime.org. 
482 hSsoFast EvaGreen ${ }^{\circledR}$ supermix, Bio-Rad Laboratories, CA USA.

483 iWest Coast Metabolomics Core, University of California, Davis, CA USA.

484 jPRIMER 6, PRIMER-E Ltd, Ivybridge, UK.

485 kMetaboAnalyst 3.0. Available at: http://www.metaboanalyst.ca.

$486{ }^{1}$ MedCalc 15.8 MedCalc Software, Ostend, Belgium.

487 mSAS 9.4 release TS1M3, SAS Institute Inc., Cary, NC USA.

488

489 References

490 Abecia L, Hoyles L, Khoo C, Frantz N, and McCartney AL. 2010. Effects of a novel

491 galactooligosaccharide on the faecal microbiota of healthy and inflammatory bowel disease

492 cats during a randomized, double-blind, cross-over feeding study. Int J Probiotics Prebiotics $493 \quad 5: 61-68$.

494 Adams VJ, Campbell JR, Waldner CL, Dowling PM, and Shmon CL. 2005. Evaluation of client 495 compliance with short-term administration of antimicrobials to dogs. Journal of the 496 American Veterinary Medical Association 226:567-574.

497 Alam MA, Subhan N, Hossain H, Hossain M, Reza HM, Rahman MM, and Ullah MO. 2016.

498 Hydroxycinnamic acid derivatives: a potential class of natural compounds for the 499 management of lipid metabolism and obesity. Nutrition \& Metabolism 13:27.

$500 \quad 10.1186 / \mathrm{s} 12986-016-0080-3$

501 Albarellos GA, and Landoni MF. 2009. Current concepts on the use of antimicrobials in cats. $502 \quad$ Veterinary Journal 180:304-316.

503 AlShawaqfeh MK, Wajid B, Minamoto Y, Markel M, Lidbury JA, Steiner JM, Serpedin E, and 504 Suchodolski JS. 2017. A dysbiosis index to assess microbial changes in fecal samples of dogs 
505

506

507

508

509

510

511

512

513

514

515

516

517

518

519

520

521

522

523

524

525

526

527

with chronic inflammatory enteropathy. FEMS Microbiology Ecology 93:fix 136-fix136. 10.1093/femsec/fix 136

Aniwan S, Tremaine WJ, Raffals LE, Kane SV, and Loftus JEV. 2018. Antibiotic use and newonset inflammatory bowel disease in Olmsted County, Minnesota: A population-based casecontrol study. Journal of Crohn's and Colitis 12:137-144. 10.1093/ecco-jcc/jjx135

Bansal T, Alaniz RC, Wood TK, and Jayaraman A. 2010. The bacterial signal indole increases epithelial-cell tight-junction resistance and attenuates indicators of inflammation. Proceedings of the National Academy of Sciences of the United States of America 107:228233. 10.1073/pnas.0906112107

Bansal T, Englert D, Lee J, Hegde M, Wood TK, and Jayaraman A. 2007. Differential effects of epinephrine, norepinephrine, and indole on Escherichia coli O157:H7 chemotaxis, colonization, and gene expression. Infection and Immunity 75:4597-4607.

Bartlett JG. 2002. Antibiotic-associated diarrhea. New Engl J Med 346:334-339.

Bell ET, Suchodolski JS, Isaiah A, Fleeman LM, Cook AK, Steiner JM, and Mansfield CS.

2014. Faecal microbiota of cats with insulin-treated diabetes mellitus. PloS One 9:e108729. 10.1371/journal.pone.0108729

Biagi G, Cipollini I, Bonaldo A, Grandi M, Pompei A, Stefanelli C, and Zaghini G. 2013. Effect of feeding a selected combination of galacto-oligosaccharides and a strain of Bifidobacterium pseudocatenulatum on the intestinal microbiota of cats. American Journal of Veterinary Research 74:90-95.

Bureau of Veterinary Drugs. 1995. Suspected drug adverse reactions reported to the Bureau of Veterinary Drugs. Canadian Veterinary Journal 36:246-249.

Chan YH, Fan MM, Fok CM, Lok ZL, Ni M, Sin CF, Wong KK, Wong SM, Yeung R, Yeung 
528 TT, Chow WC, Lam TH, and Schooling CM. 2012. Antibiotics nonadherence and

529 knowledge in a community with the world's leading prevalence of antibiotics resistance:

530 implications for public health intervention. American Journal of Infection Control 40:113-

$531 \quad 117$.

532 Chao R, Khan W, and Hannun YA. 1992. Retinoblastoma protein dephosphorylation induced by

533 D-erythro-sphingosine. Journal of Biological Chemistry 267:23459-23462.

534 Col N, Fanale JE, and Kronholm P. 1990. The role of medication noncompliance and adverse

535 drug reactions in hospitalizations of the elderly. Archives of Internal Medicine 150:841-845.

536 de La Cochetière MF, Montassier E, Hardouin JB, Carton T, Le Vacon F, Durand T, Lalande V,

537 Petit JC, Potel G, and Beaugerie L. 2010. Human intestinal microbiota gene risk factors for

538 antibiotic-associated diarrhea: perspectives for prevention. Risk factors for antibiotic-

$539 \quad$ associated diarrhea. Microbial Ecology 59:830-837. 10.1007/s00248-010-9637-2

540 Desai AR, Musil KM, Carr AP, and Hill JE. 2009. Characterization and quantification of feline

541 fecal microbiota using cpn60 sequence-based methods and investigation of animal-to-animal

542 variation in microbial population structure. Veterinary Microbiology 137:120-128.

543 Dethlefsen L, Huse S, Sogin ML, and Relman DA. 2008. The pervasive effects of an antibiotic

544 on the human gut microbiota, as revealed by deep 16S rRNA sequencing. PLoS Biology

$545 \quad 6: e 280.10 .1371 /$ journal.pbio.0060280

546 Duboc H, Rajca S, Rainteau D, Benarous D, Maubert MA, Quervain E, Thomas G, Barbu V,

547 Humbert L, Despras G, Bridonneau C, Dumetz F, Grill JP, Masliah J, Beaugerie L, Cosnes J,

548 Chazouillères O, Poupon R, Wolf C, Mallet JM, Langella P, Trugnan G, Sokol H, and Seksik

549 P. 2013. Connecting dysbiosis, bile-acid dysmetabolism and gut inflammation in

550 inflammatory bowel diseases. Gut 62:531-539. 
551 European Food Safety Authority. 2012. EFSA Panel on Additives and Products or Substances

552 used in Animal Feed Scientific. Opinion on the safety and efficacy of Prostora Max

553 (Bifidobacterium animalis) as a feed additive for dogs. EFSA Journal 10:2964-2978.

554 Fiehn O, Wohlgemuth G, Scholz M, Kind T, Lee DY, Lu Y, Moon S, and Nikolau B. 2008.

555 Quality control for plant metabolomics: reporting MSI-compliant studies. Plant Journal

$556 \quad 53: 691-704.10 .1111 / \mathrm{j} .1365-313 X .2007 .03387 . \mathrm{x}$

557 Fujiwara N, Porcelli SA, Naka T, Yano I, Maeda S, Kuwata H, Akira S, Uematsu S, Takii T,

558 Ogura H, and Kobayashi K. 2013. Bacterial sphingophospholipids containing non-hydroxy

559 fatty acid activate murine macrophages via Toll-like receptor 4 and stimulate bacterial

$560 \quad$ clearance. Biochimica et Biophysica Acta 1831:1177-1184. 10.1016/j.bbalip.2013.03.008

561 Garcia-Mazcorro JF, Lanerie DJ, Dowd SE, Paddock CG, Grutzner N, Steiner JM, Ivanek R, and

562 Suchodolski JS. 2011. Effect of a multi-species synbiotic formulation on fecal bacterial

563 microbiota of healthy cats and dogs as evaluated by pyrosequencing. FEMS Microbiology

564 Ecology 78:542-554.

565 Goldenberg JZ, Lytvyn L, Steurich J, Parkin P, Mahant S, and Johnston BC. 2015. Probiotics for 566 the prevention of pediatric antibiotic-associated diarrhea (Review). Cochrane Database Syst 567 Rev:CD004827. 10.1002/14651858.CD004827.pub4

568 Greco DS. 2011. Diagnosis and dietary management of gastrointestinal disease. Available at 569 https://www.purinaveterinarydiets.com/media/1202/gi quick reference guide.pdf(accessed $570 \quad$ September 29, 2017 2017).

571 Gustafsson A, Lund-Tønnesen S, Berstad A, Midtvedt T, and Norin E. 1998. Faecal short-chain 572 fatty acids in patients with antibiotic-associated diarrhoea, before and after faecal enema 573 treatment. Scandinavian Journal of Gastroenterology 33:721-727. 
574 Hart ML, Suchodolski JS, Steiner JM, and Webb CB. 2012. Open-label trial of a multi-strain 575 synbiotic in cats with chronic diarrhea. Journal of Feline Medicine and Surgery 14:240-245.

576 Hempel S, Newberry SJ, Maher AR, Wang Z, Miles JN, Shanman R, Johnsen B, and Shekelle 577 PG. 2012. Probiotics for the prevention and treatment of antibiotic-associated diarrhea: a 578 systematic review and meta-analysis. Journal of the American Medical Association $579 \quad 307: 1959-1969$.

580 Honneffer J, Guard B, Steiner JM, and Suchodolski JS. 2015. Untargeted metabolomics reveals 581 disruption within bile acid, cholesterol, and tryptophan metabolic pathways in dogs with 582 idiopathic inflammatory bowel disease (abstr.). Gastroenterology 148 (Suppl. 1):S-715 583 (Abstract Mo1805).

584 Honneffer JB, Steiner JM, Lidbury JA, and Suchodolski JS. 2017. Variation of the microbiota 585 and metabolome along the canine gastrointestinal tract. Metabolomics 13:26.

$586 \quad 10.1007 / \mathrm{s} 11306-017-1165-3$

587 Hunter RP, Lynch MJ, Ericson JF, Millas WJ, Fletcher AM, Ryan NI, and Olson JA. 1995.

588 Pharmacokinetics, oral bioavailability and tissue distribution of azithromycin in cats. Journal 589 of Veterinary Pharmacology and Therapeutics 18:38-46.

590 Jakobsson HE, Jernberg C, Andersson AF, Sjolund-Karlsson M, Jansson JK, and Engstrand L. 591 2010. Short-term antibiotic treatment has differing long-term impacts on the human throat $592 \quad$ and gut microbiome. PloS One 5:e9836. 10.1371/journal.pone.0009836

593 Jefferds MD, Laserson K, Fry AM, Roy S, Hayslett J, Grummer-Strawn L, Kettel-Khan L, 594 Schuchat A, and Team smotCfDCaPAA. 2002. Adherence to antimicrobial inhalational 595 anthrax prophylaxis among postal workers, Washington, D.C., 2001. Emerging Infectious 596 Diseases 8:1138-1144. 
597 Jia J, Frantz N, Khoo C, Gibson GR, Rastall RA, and McCartney AL. 2011a. Investigation of the 598 faecal microbiota of geriatric cats. Letters in Applied Microbiology 53:288-293.

599 Jia J, Frantz N, Khoo C, Gibson GR, Rastall RA, and McCartney AL. 2011b. Investigation of the 600 faecal microbiota of kittens: monitoring bacterial succession and effect of diet. FEMS 601 Microbiology Ecology 78:395-404.

602 Johnston BC, Goldenberg JZ, Vandvik PO, Sun X, and Guyatt GH. 2011. Probiotics for the 603 prevention of pediatric antibiotic-associated diarrhea. Cochrane Database Syst Rev $604 \quad 10.1002 / 14651858 . C D 004827 . p u b 3$

605 Kardas P, Devine S, Golembesky A, and Roberts C. 2005. A systematic review and meta606 analysis of misuse of antibiotic therapies in the community. International Journal of 607 Antimicrobial Agents 26:106-113.

608 Koeppel KN, Bertschinger H, van Vuuren M, Picard J, Steiner JM, Williams D, and Cardwell J. 609 2006. The use of a probiotic in captive cheetahs (Acinonyx jubatus). Journal of the South 610 African Veterinary Association 77:127-130.

611 Kronman MP, Zaoutis TE, Haynes K, Feng R, and Coffin SE. 2012. Antibiotic exposure and 612 IBD development among children: A population-based cohort study. Pediatrics 130:e794613 e803. $10.1542 /$ peds.2011-3886

614 Lau CSM, and Chamberlain RS. 2016. Probiotics are effective at preventing Clostridium 615 difficile-associated diarrhea: a systematic review and meta-analysis. International Journal of 616 General Medicine 9:27-37. 10.2147/IJGM.S98280

617 Lenoir-Wijnkoop I, Nuijten MJ, Craig J, and Butler CC. 2014. Nutrition economic evaluation of 618 a probiotic in the prevention of antibiotic-associated diarrhea. Frontiers in Pharmacology $619 \quad 5: 13.10 .3389 /$ fphar.2014.00013 
620 Llor C, Hernandez S, Bayona C, Moragas A, Sierra N, Hernandez M, and Miravitlles M. 2013. A

621 study of adherence to antibiotic treatment in ambulatory respiratory infections. International 622 Journal of Infectious Diseases 17:e168-172.

623 Löfmark S, Jernberg C, Jansson JK, and Edlund C. 2006. Clindamycin-induced enrichment and 624 long-term persistence of resistant Bacteroides spp. and resistance genes. Journal of 625 Antimicrobial Chemotherapy 58:1160-1167.

626 Manuja R, Sachdeva S, Jain A, and Chaudhary J. 2013. A comprehensive review on biological 627 activities of P-hydroxy benzoic acid and its derivatives. Int J Pharm Sci Rev Res 22:109-115. 628 Marshall-Jones ZV, Baillon ML, Croft JM, and Butterwick RF. 2006. Effects of Lactobacillus 629 acidophilus DSM13241 as a probiotic in healthy adult cats. American Journal of Veterinary $630 \quad$ Research 67:1005-1012.

631 McFarland LV. 2008. Antibiotic-associated diarrhea: epidemiology, trends, and treatment. $632 \quad$ Future Microbiology 3:563-578.

633 McFarland LV. 2009. Evidence-based review of probiotics for antibiotic-associated diarrhea and 634 Clostridium difficile infections. Anaerobe 15:274-280. 10.1016/j.anaerobe.2009.09.002

635 McFarland LV. 2016. An observation on inappropriate probiotic subgroup classifications in the 636 meta-analysis by Lau and Chamberlain. International Journal of General Medicine 9:333637336.

638 Mikkelsen KH, Knop FK, Vilsbøll T, Frost M, Hallas J, and Pottegård A. 2016. Use of 639 antibiotics in childhood and risk of Type 1 diabetes: a population-based case-control study. $640 \quad$ Diabetic Medicine 34:272-277. 10.1111/dme.13262

641 Minamino M, Sakaguchi I, Naka T, Ikeda N, Kato Y, Tomiyasu I, Yano I, and Kobayashi K. 642 2003. Bacterial ceramides and sphingophospholipids induce apoptosis of human leukaemic 
$643 \quad$ cells. Microbiology 149:2071-2081.

644 Minamoto Y, Otoni CC, Steelman SM, Büyükleblebici O, Steiner JM, Jergens AE, and

645 Suchodolski JS. 2015. Alteration of the fecal microbiota and serum metabolite profiles in

646 dogs with idiopathic inflammatory bowel disease. Gut Microbes 6:33-47.

$647 \quad 10.1080 / 19490976.2014 .997612$

648 Minois N, Carmona-Gutierrez D, and Madeo F. 2011. Polyamines in aging and disease. Aging 649 (Albany NY) 3:716-732.

650 Muñoz EB, Dorado MF, Guerrero JE, and Martinez FM. 2014. The effect of an educational

651 intervention to improve patient antibiotic adherence during dispensing in a community 652 pharmacy. Atencion Primaria 46:367-375.

653 Narayan SS, Jalgaonkar S, Shahani S, and Kulharni VN. 2010. Probiotics: current trends in the 654 treatment of diarrhoea. Hong Kong Medical Journal Xianggang Yi Xue Za Zhi 16:213-218.

655 Ohland CL, and MacNaughton WK. 2010. Probiotic bacteria and intestinal epithelial barrier 656 function. American Journal of Physiology: Gastrointestinal and Liver Physiology 298:G807657 G819.

658 Ouwehand AC, Forssten S, Hibberd AA, Lyra A, and Stahl B. 2016. Probiotic approach to 659 prevent antibiotic resistance. Annals of Medicine 48:246-255.

$660 \quad 10.3109 / 07853890.2016 .1161232$

661 Pagnini C, Saeed R, Bamias G, Arseneau KO, Pizarro TT, and Cominelli F. 2010. Probiotics

662 promote gut health through stimulation of epithelial innate immunity. Proc Natl Acad Sci $663 \quad$ USA 107:454-459. 10.1073/pnas.0910307107

664 Pechere JC, Hughes D, Kardas P, and Cornaglia G. 2007. Non-compliance with antibiotic 665 therapy for acute community infections: a global survey. International Journal of 
667 Quigley EM. 2012. Prebiotics and probiotics: their role in the management of gastrointestinal 668 disorders in adults. Nutrition in Clinical Practice 27:195-200. 10.1177/0884533611423926

669 Ramadan Z, Xu H, Laflamme D, Czarnecki-Maulden G, Li QJ, Labuda J, and Bourqui B. 2014. 670 Fecal microbiota of cats with naturally occurring chronic diarrhea assessed using 16S rRNA 671 gene 454-pyrosequencing before and after dietary treatment. Journal of Veterinary Internal $672 \quad$ Medicine 28:59-65.

673 Rossi G, Pengo G, Caldin M, Piccionello AP, Steiner JM, Cohen ND, Jergens AE, and 674 Suchodolski JS. 2014. Comparison of microbiological, histological, and immunomodulatory 675 parameters in response to treatment with either combination therapy with prednisone and 676 metronidazole or probiotic VSL\#3 strains in dogs with idiopathic inflammatory bowel 677 disease. PloS One 9:e94699. 10.1371/journal.pone.0094699

678 Schubert AM, Rogers MAM, Ring C, Mogle J, Petrosino JP, Young VB, Aronoff DM, and 679 Schloss PD. 2014. Microbiome data distinguish patients with Clostridium difficile infection 680 and non-C. difficile-associated diarrhea from healthy controls. mBio 5:e01021-01014. 681 doi:10.1128/mBio.01021-14

682 Scott FI, Horton DB, Mamtani R, Haynes K, Goldberg DS, Lee DY, and Lewis JD. 2016.

683 Administration of antibiotics to children before age 2 years increases risk for childhood 684 obesity. Gastroenterology 151:120-129.e125. 10.1053/j.gastro.2016.03.006

685 Selinger CP, Bell A, Cairns A, Lockett M, Sebastian S, and Haslam N. 2013. Probiotic VSL\#3 686 prevents antibiotic-associated diarrhoea in a double-blind, randomized, placebo-controlled 687 clinical trial. Journal of Hospital Infection 84:159-165.

688 Šlapeta J, Dowd SE, Alanazi AD, Westman ME, and Brown GK. 2015. Differences in the faecal 
689

690

691

692

693

694

695

696

697

698

699

700

701

702

703

704

705

706

707

708

709

710

711

microbiome of non-diarrhoeic clinically healthy dogs and cats associated with Giardia duodenalis infection: impact of hookworms and coccidia. International Journal for Parasitology 45:585-594. 10.1016/j.ijpara.2015.04.001

Stokes JE, Price JM, and Whittemore JC. 2017. Randomized, controlled, crossover trial of prevention of clindamycin-induced gastrointestinal signs using a synbiotic in healthy research cats. Journal of Veterinary Internal Medicine 31:1406-1413.

Strompfová V, Lauková A, and Ouwehand AC. 2004. Selection of enterococci for potential canine probiotic additives. Veterinary Microbiology 100:107-114.

Suchodolski JS. 2016a. Diagnosis and interpretation of intestinal dysbiosis in dogs and cats. Vet $J$ S1090-0233:30033-30038. 10.1016/j.tvj1.2016.04.011

Suchodolski JS. 2016b. Diagnosis and interpretation of intestinal dysbiosis in dogs and cats. The Veterinary Journal 215:30-37. http://dx.doi.org/10.1016/j.tvj1.2016.04.011

Suchodolski JS, Dowd SE, Westermarck E, Steiner JM, Wolcott RD, Spillman T, and Harmoinen JA. 2009. The effect of the macrolide antibiotic tylosin on microbial diversity in the canine small intestine as demonstrated by massive parallel 16S rRNA gene sequencing. BMC Microbiology 9:210. 10.1186/1471-2180-9-210

Suchodolski JS, Foster ML, Sohail MU, Leutenegger C, Queen EV, Steiner JM, and Marks SL. 2015. The fecal microbiome in cats with diarrhea. PloS One 10:e127378.

10.1371/journal.pone.0127378

Suchodolski JS, Markel ME, Garcia-Mazcorro JF, Unterer S, Heilmann RM, Dowd SE, Kachroo P, Ivanov I, Minamoto Y, Dillman EM, Steiner JM, Cook AK, and Toresson L. 2012. The fecal microbiome in dogs with acute diarrhea and idiopathic inflammatory bowel disease. PloS One 7:e51907. 
712 Szajewska H, Konarska Z, and Kołodziej M. 2016. Probiotic bacterial and fungal strains: claims

713 with evidence. Digestive Diseases 34:251-259.

714 van den Bemt PM, Chaaouit N, van Lieshout EM, and Verhofstad MH. 2016. Noncompliance

715 with guidelines on proton pump inhibitor prescription as gastroprotection in hospitalized

716 surgical patients who are prescribed NSAIDs. European Journal of Gastroenterology and

717 Hepatology 28:857-862. 10.1097/MEG.0000000000000634

718 Varughese CA, Vakil NH, and Phillips KM. 2013. Antibiotic-associated diarrhea: a refresher on

719 causes and possible prevention with probiotics--continuing education article. Journal of

$720 \quad$ Pharmacy Practice 26:476-482.

721 Vesper H, Schmelz EM, Nikolova-Karakashian MN, Dillehay DL, Lynch DV, and Merrill AHJ.

722 1999. Sphingolipids in food and the emerging importance of sphingolipids to nutrition.

723 Journal of Nutrition 129:1239-1250.

724 Videlock EJ, and Cremonini F. 2012. Meta-analysis: probiotics in antibiotic-associated diarrhea.

725 Alimentary Pharmacology and Therapeutics 35:1355-1369.

726 Weese JS, Nichols J, Jalali M, and Litster A. 2015. The rectal microbiota of cats infected with

727 feline immunodeficiency virus infection and uninfected controls. Veterinary Microbiology

$728 \quad$ 180:96-102. 10.1016/j.vetmic.2015.08.012

729 Woodmansey EJ, McMurdo ME, Macfarlane GT, and Macfarlane S. 2004. Comparison of

730 compositions and metabolic activities of fecal microbiotas in young adults and in antibiotic-

731 treated and non-antibiotic-treated elderly subjects. Applied and Environmental Microbiology

$732 \quad 70: 6113-6122$.

733 Xia J, Sinelnikov I, Han B, and Wishart DS. 2015. MetaboAnalyst 3.0 - making metabolomics

734 more meaningful. Nucl Acids Res 43:W251-257. 
735 Xia J, and Wishart DS. 2011. Web-based inference of biological patterns, functions and 736 pathways from metabolomic data using MetaboAnalyst. Nature Protocols 6:743-760.

737

738 


\section{Figure 1 (on next page)}

Flowchart illustrating study design, duration, observations, and sampling.

The study spanned 633 days (D1-633) and was broken into 3 study periods: baseline (D1D7), treatment (D8-D28), and washout. Cats were randomized to receive either a placebo or synbiotic with $150 \mathrm{mg}$ clindamycin PO once daily during treatment. Food intake, vomiting, and fecal score were recorded daily $(\cdot)$ and weight (W) weekly $(*)$ by an individual blinded to treatment group. 2 grams were collected from the center portion of each first morning naturally-voided fecal samples for each cat once daily for the last 3 days of each study period: baseline (open circles), treatment (open squares), and recovery (open diamonds). Each sample was subdivided into 2 aliquots, with each aliquot placed into a $2 \mathrm{~mL}$ cryovial and immediately frozen at $-80^{\circ} \mathrm{C}$ pending completion of data collection. 


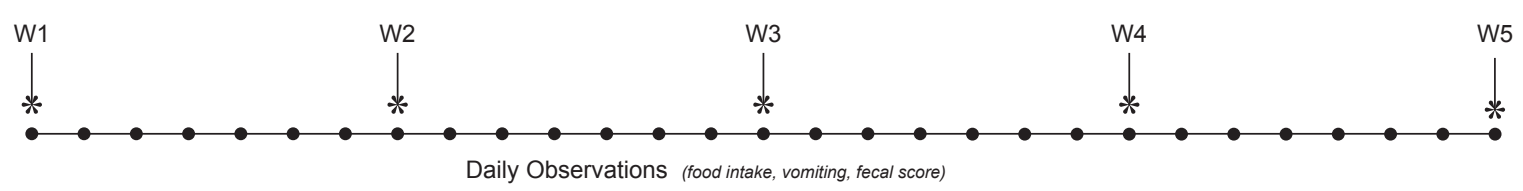

$\begin{array}{llllllllllllllllllllllllllllllllllllllll}\text { D0 } & \text { D1 } & \text { D2 } & \text { D3 } & \text { D4 } & \text { D5 } & \text { D6 } & \text { D7 } & \text { D8 } & \text { D9 } & \text { D10 } & \text { D11 } & \text { D12 } & \text { D13 } & \text { D14 } & \text { D15 } & \text { D16 } & \text { D17 } & \text { D18 } & \text { D19 } & \text { D20 } & \text { D21 } & \text { D22 } & \text { D23 } & \text { D24 } & \text { D25 } & \text { D26 } & \text { D27 } & \text { D28 }\end{array}$ D631 D632 D633

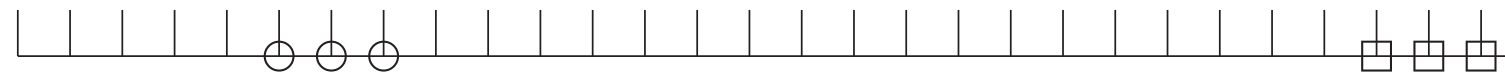
BASELINE

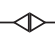
TREATMENT 
Figure 2

Principal Coordinate Analysis (PCoA) of unweighted UniFrac distances of $16 \mathrm{~S}$ rRNA genes.

Gene sequences were determined using fecal samples collected at baseline (days 5-7), at the conclusion of antibiotic administration (days 26-28), and after a 603 day washout (days 631633) from 16 healthy cats, 8 per group, ${ }^{+}$that received $150 \mathrm{mg}$ clindamycin with either a placebo or synbiotic PO once daily for 21 days. ${ }^{+}$Feces from one cat (synbiotic group) unavailable on days 631-633.

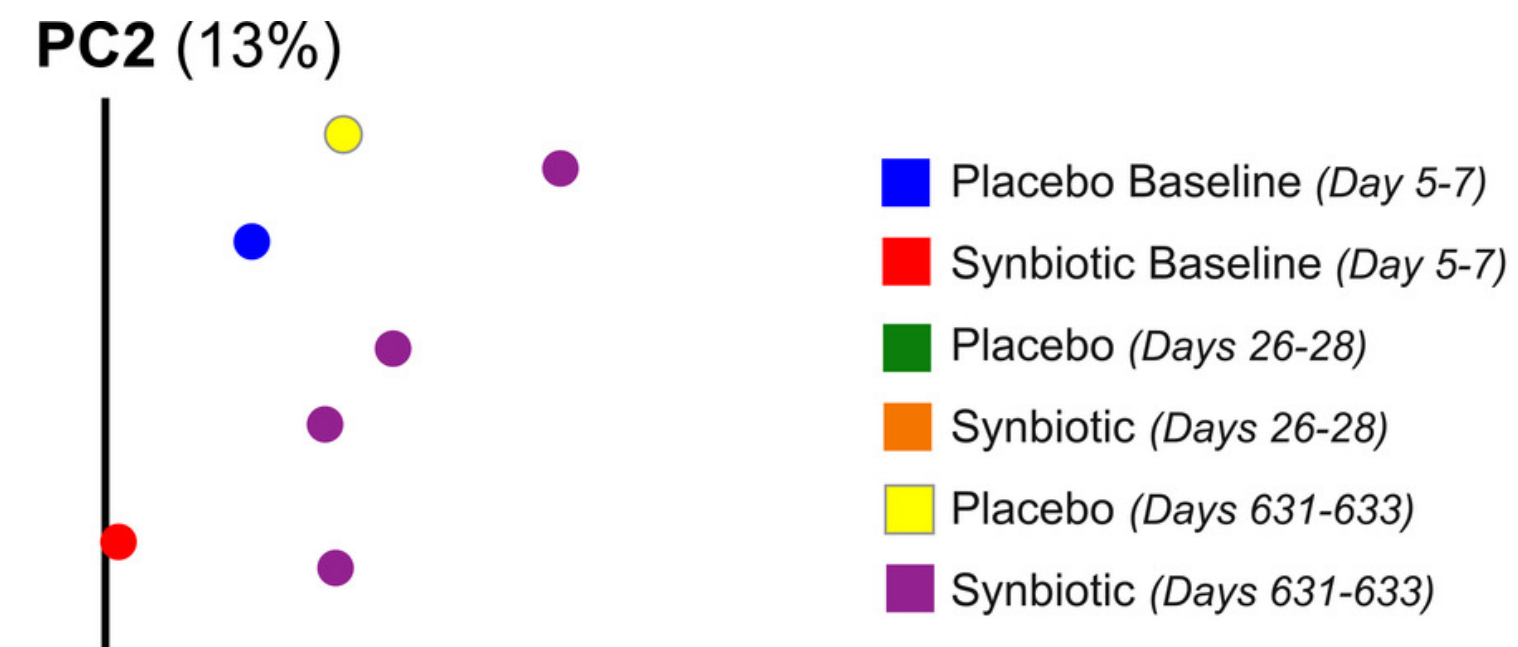

PC1 $(53 \%)$ 
Figure 3

Phylum- and class-level composition of fecal microbiota obtained from feline fecal samples.

(A) Placebo. (B) Synbiotic. Samples were collected at baseline (days 5-7), at the conclusion of antibiotic administration (days 26-28), and after a 603 day washout (days 631-633) from 16 healthy cats, 8 per group, ${ }^{+}$that received 150 mg clindamycin with either a placebo or synbiotic PO once daily for 21 days. ${ }^{+}$Feces from one cat (synbiotic group) unavailable on days 631-633. Legend for all detected classes is shown, grouped by phylum.

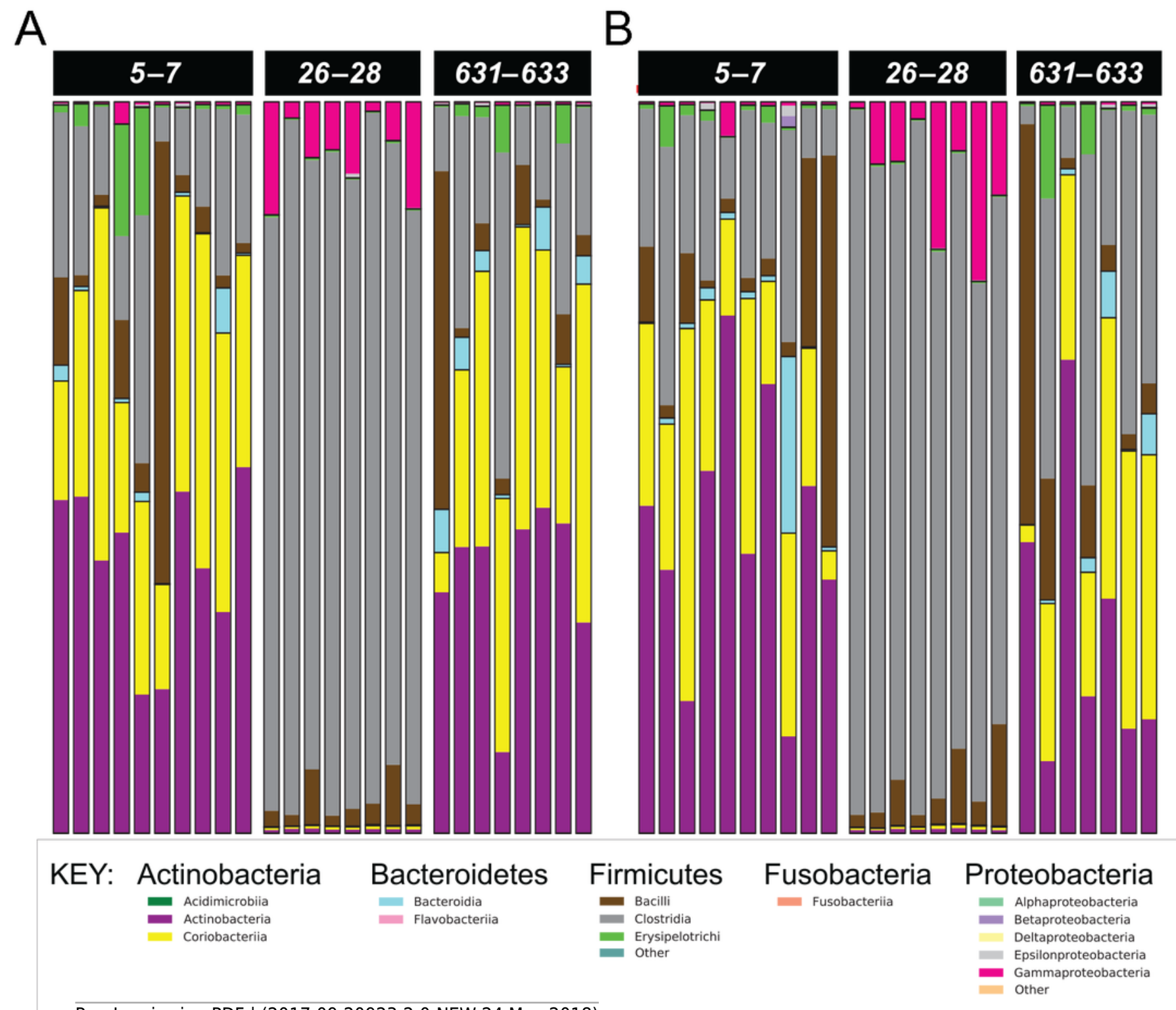




\section{Figure 4}

Dual hierarchical dendrogram of metabolites, clustered by pathway, that differed significantly over time in feline fecal samples.

Samples were collected at baseline (days 5-7), at the conclusion of antibiotic administration (days 26-28), and after a 603 day washout (days 631-633) from 16 healthy cats, 8 per group, ${ }^{+}$that received $150 \mathrm{mg}$ clindamycin with either a placebo or synbiotic PO once daily for 21 days. ${ }^{+}$Feces from one cat (synbiotic group) unavailable on days 631-633. 


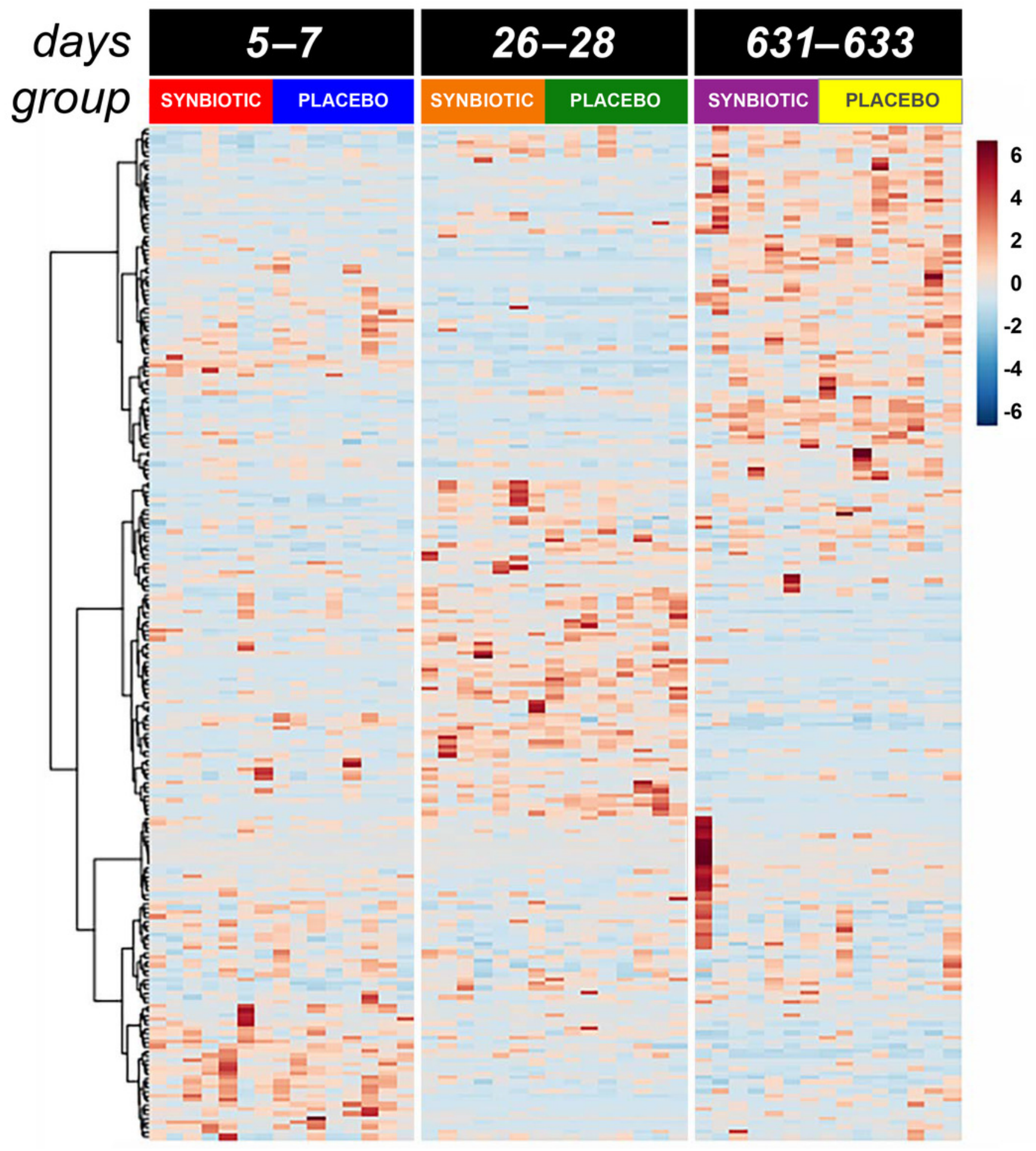


Figure 5

Principal Component Analysis (PCA) of metabolic pathway analyses from feline fecal samples

Samples were collected at baseline (days 5-7), at the conclusion of antibiotic administration (days 26-28), and after a 603 day washout (days 631-633) from 16 healthy cats, 8 per group, ${ }^{+}$that received $150 \mathrm{mg}$ clindamycin with either a placebo or synbiotic PO once daily for 21 days. ${ }^{+}$Feces from one cat (synbiotic group) unavailable on days 631-633.

PC2 (11.8\%)

GROUP: $\square$ PLACEBO O SYNBIOTIC

DAYS: $\bigcirc 5-7 \quad \bigcirc 26-28 \quad \bigcirc 631-633$

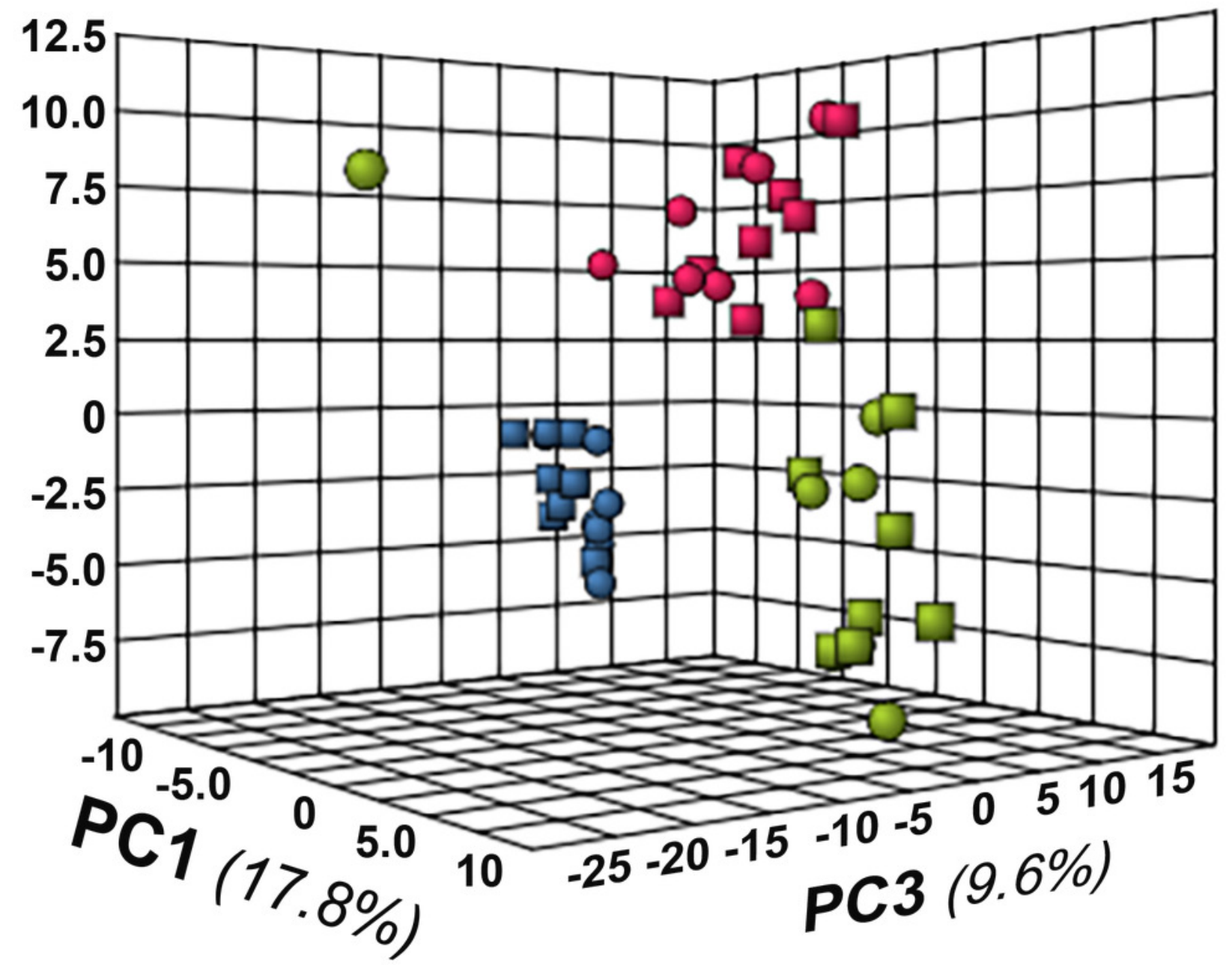




\section{Figure 6}

Box and whisker plots of fecal metabolite profiles for 7 fecal metabolites that differed significantly (fdr adjusted $P<0.05$ ) between treatment groups and over time.

(A) Putrescine. (B) Isopentadecanoic acid. (C) Cellobiose. (D) Lactose. (E) Ethanolamine. (F) D-erythro-sphingosine. (G) N-acetylglutamate. Medians, interquartile ranges, and minimum and maximum values are presented for cats in the placebo (boxes with solid borders) and synbiotic (boxes with dashed borders) treatment groups. Open circles and closed triangles denote outlier values. Boxes that do not share a letter differed significantly (fdr-adjusted $P<$ 0.05 ) based on post-hoc analysis. Fecal samples were collected at baseline (days 5-7), at the conclusion of antibiotic administration (days 26-28), and after a 603 day washout (days 631633) from 16 healthy cats, 8 per group, ${ }^{+}$that received $150 \mathrm{mg}$ clindamycin with either a placebo or synbiotic PO once daily for 21 days. ${ }^{+}$Feces from one cat (synbiotic group) unavailable on days 631-633. Significance was set as $P<0.05$, with $P$-values adjusted based on the Benjamini and Hochberg False discovery rate (fdr).
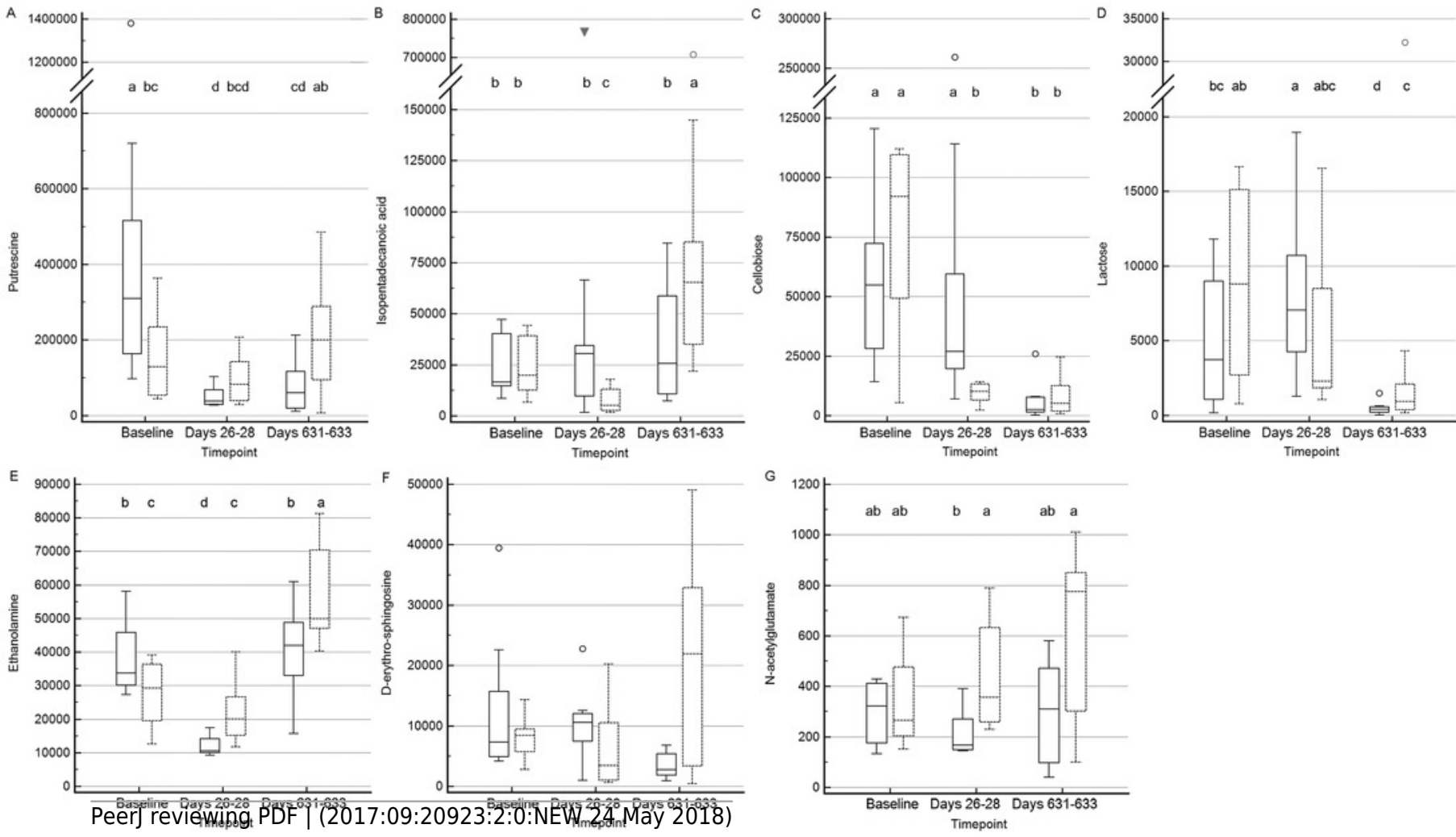


\section{Table $\mathbf{1}$ (on next page)}

Target bacteria, oligonucleotide primers/probes, and annealing temperatures used for quantitative PCR analysis. 


\begin{tabular}{|c|c|c|c|}
\hline Target & $\begin{array}{l}\text { Primer } \\
\text { type }\end{array}$ & Sequence $\left(5^{\prime}-3^{\prime}\right)$ & $\begin{array}{c}\text { Annealing } \\
\left({ }^{\circ} \mathrm{C}\right)\end{array}$ \\
\hline \multirow{2}{*}{ Universal bacteria } & Forward & CCTACGGGAGGCAGCAGT & \multirow{2}{*}{59} \\
\hline & Reverse & ATTACCGCGGCTGCTGG & \\
\hline \multirow{2}{*}{ Blautia spp. } & Forward & TCTGATGTGAAAGGCTGGGGCTTA & \multirow{2}{*}{56} \\
\hline & Reverse & GGCTTAGCCACCCGACACCTA & \\
\hline \multirow{2}{*}{ Clostridium hiranonis } & Forward & AGTAAGCTCCTGATACTGTCT & \multirow{2}{*}{50} \\
\hline & Reverse & AGGGAAAGAGGAGATTAGTCC & \\
\hline \multirow{2}{*}{ Escherichia coli } & Forward & GTTAATACCTTTGCTCATTGA & \multirow{2}{*}{55} \\
\hline & Reverse & ACCAGGGTATCTAATCCTGTT & \\
\hline \multirow{2}{*}{$\begin{array}{l}\text { Faecalibacterium } \\
\text { spp. }\end{array}$} & Forward & GAAGGCGGCCTACTGGGCAC & \multirow{2}{*}{60} \\
\hline & Reverse & GTGCAGGCGAGTTGCAGCCT & \\
\hline \multirow{2}{*}{ Fusobacteria spp. } & Forward & KGGGCTCAACMCMGTATTGCGT & \multirow{2}{*}{51} \\
\hline & Reverse & TCGCGTTAGCTTGGGCGCTG & \\
\hline \multirow{2}{*}{ Streptococcus spp. } & Forward & TTATTTGAAAGGGGCAATTGCT & \multirow{2}{*}{54} \\
\hline & Reverse & GTGAACTTTCCACTCTCACAC & \\
\hline \multirow{2}{*}{ Turicibacter spp. } & Forward & CAGACGGGGACAACGATTGGA & \multirow{2}{*}{63} \\
\hline & Reverse & TACGCATCGTCGCCTTGGTA & \\
\hline
\end{tabular}

1 


\section{Table 2 (on next page)}

Antibiotic-associated gastrointestinal signs for cats that received clindamycin and a placebo or synbiotic.

Mean ( \pm standard deviation) percent food intake compared to the week prior to initiation of the study, percent days vomiting per week, and fecal score for 16 healthy cats, 8 per group, that received $150 \mathrm{mg}$ clindamycin with either a placebo or synbiotic PO once daily for 21 days. 
1

\begin{tabular}{|l|c|c|c|c|}
\hline & \multirow{2}{*}{ Baseline } & \multicolumn{3}{|c|}{ Treatment } \\
\cline { 3 - 5 } & & Week 1 & Week 2 & Week 3 \\
\hline Food intake (\%) & & & & \\
$-\quad$ Placebo & $97.8 \pm 4.1$ & $89.9 \pm 5.5$ & $89.7 \pm 11.3$ & $88.1 \pm 13.2$ \\
$-\quad$ Synbiotic & $98.3 \pm 4.1$ & $92.7 \pm 8.2$ & $94.1 \pm 8.4$ & $92.7 \pm 11.1$ \\
\hline Vomiting (\%) & & & & \\
$-\quad$ Placebo & $0 \pm 0$ & $26.8 \pm 22.2$ & $14.3 \pm 20.2$ & $9.0 \pm 17.0$ \\
$-\quad$ Synbiotic & $1.8 \pm 5.1$ & $21.5 \pm 15.3$ & $9.0 \pm 15.2$ & $1.8 \pm 5.1$ \\
\hline Fecal score & & & $3.5 \pm 0.8$ & $3.7 \pm 1.3$ \\
$-\quad$ Placebo & $2.6 \pm 0.8$ & $3.2 \pm 0.8$ & $3.8 \pm 0.7$ & $4.2 \pm 0.4$ \\
\hline
\end{tabular}

2 


\section{Table 3 (on next page)}

Alpha diversity and dysbiosis index results for cats that received clindamycin and placebo or synbiotic.

Median (range) results for feces collected at baseline (days 5-7), at the conclusion of antibiotic administration (days 26-28), and after a 603 day washout (days 631-633) from 16 healthy cats, 8 per group, ${ }^{+}$that received $150 \mathrm{mg}$ clindamycin with either a placebo or synbiotic PO once daily for 21 days. ${ }^{+}$Feces from one cat (synbiotic group) unavailable at the days 631-633 timepoint. Cells that do not share a common superscript letter differed significantly $(P<0.05)$ based on post-hoc analysis. 
1

\begin{tabular}{|l|c|c|c|c|c|c|c|}
\hline & \multicolumn{2}{|c|}{ Baseline } & \multicolumn{2}{c|}{ Days 26-28 } & \multicolumn{2}{c|}{ Days 631-633 } & \multirow{2}{*}{$\begin{array}{c}\text { P- } \\
\text { value }\end{array}$} \\
\cline { 2 - 7 } & Placebo & Synbiotic & Placebo & Synbiotic & Placebo & Synbiotic & value \\
\hline Shannon & $3.9^{\mathrm{a}}$ & $4.2^{\mathrm{a}}$ & $2.5^{\mathrm{b}}$ & $2.8^{\mathrm{b}}$ & $4^{\mathrm{a}}$ & $4.9^{\mathrm{a}}$ & $<0.001$ \\
index & $(3.3-5.3)$ & $(3.5-4.8)$ & $(1.8-3.0)$ & $(2.1-3.1)$ & $(3.6-5.2)$ & $(3.0-5.6)$ & \\
Goods & $0.9859^{\mathrm{a}}$ & $0.9857^{\mathrm{a}}$ & $0.9906^{\mathrm{b}}$ & $0.9907^{\mathrm{b}}$ & $0.9858^{\mathrm{a}}$ & $0.9866^{\mathrm{a}}$ & \\
coverage & $(0.9794-$ & $(0.9819-$ & $(0.9870-$ & $(0.9875-$ & $(0.9809-$ & $(0.9815-$ & $<0.001$ \\
& $0.9919)$ & $0.9920)$ & $0.9942)$ & $0.9927)$ & $0.9909)$ & $0.9894)$ & \\
\hline \multirow{3}{*}{ Chao1 metric } & $2,085^{\mathrm{a}}$ & $1,960^{\mathrm{a}}$ & $1,419^{\mathrm{b}}$ & $1,408^{\mathrm{b}}$ & $2,119^{\mathrm{a}}$ & $1,976^{\mathrm{a}}$ & \\
& $(1,126-$ & $(1,044-$ & $(830-$ & $(1,043-$ & $(1,272-$ & $(1,349-$ & $<0.001$ \\
& $3,158)$ & $2,930)$ & $2,026)$ & $2,062)$ & $2,945)$ & $2,622)$ & \\
\multirow{2}{*}{ Dysbiosis } & $-2.9^{\mathrm{c}}$ & $-3.0^{\mathrm{c}}$ & $1.6^{\mathrm{b}}$ & $4.7^{\mathrm{a}}$ & $-2.6^{\mathrm{c}}$ & $-4.4^{\mathrm{c}}$ & \\
index & $(-5.5$ to & $(-5.2$ to & $(0.4$ to & $(1.1$ to & $(-5.1$ to & $(-5.2$ to & $<0.001$ \\
& $-1.6)$ & $-0.2)$ & $3.3)$ & $5.4)$ & $-1.0)$ & $-0.4)$ & \\
\hline
\end{tabular}

2 


\section{Table 4(on next page)}

Median percent abundance (range) for taxa with significantly different relative abundances over time.

Median (range) percent relative abundances of different taxa in feces were collected at baseline (days 5-7), at the conclusion of antibiotic administration (days 26-28), and after a 603 day washout (days 631-633) from 16 healthy cats, 8 per group, ${ }^{+}$that received $150 \mathrm{mg}$ clindamycin with either a placebo or synbiotic PO once daily for 21 days. ${ }^{+}$Feces from one cat (synbiotic group) unavailable at the days 631-633 timepoint. *P-values adjusted based on the Benjamini and Hochberg False discovery rate (fdr). Relative abundances that do not share a common superscript letter differed significantly (fdr-adjusted $P<0.05$ ) based on post-hoc analysis. 


\begin{tabular}{|c|c|c|c|c|c|c|c|}
\hline & & eline & Days & 26-28 & Days & $31-633$ & Fdr- \\
\hline & Placebo & Synbiotic & Placebo & Synbiotic & Placebo & Synbiotic & $\begin{array}{c}\text { P- } \\
\text { value* }\end{array}$ \\
\hline Actinobacteria & $\begin{array}{l}68.02^{\mathrm{a}} \\
(34.02- \\
87.12)\end{array}$ & $\begin{array}{l}71.32^{\mathrm{a}} \\
(55.95- \\
83.97)\end{array}$ & $\begin{array}{c}0.96^{\mathrm{b}} \\
(0.82- \\
1.07)\end{array}$ & $\begin{array}{c}0.92^{\mathrm{b}} \\
(0.69- \\
1.20)\end{array}$ & $\begin{array}{c}69.43^{\mathrm{a}} \\
(38.38- \\
82.91)\end{array}$ & $\begin{array}{c}51.75^{\mathrm{a}} \\
(31.39- \\
90.03)\end{array}$ & $<0.001$ \\
\hline Actinobacteria & $\begin{array}{l}68.02^{\mathrm{a}} \\
(34.02- \\
87.12)\end{array}$ & $\begin{array}{l}71.32^{\mathrm{a}} \\
(55.95- \\
83.97)\end{array}$ & $\begin{array}{c}0.96^{\mathrm{b}} \\
(0.82- \\
1.07)\end{array}$ & $\begin{array}{c}0.92^{\mathrm{b}} \\
(0.69- \\
1.20)\end{array}$ & $\begin{array}{c}69.43^{\mathrm{a}} \\
(38.38- \\
82.91)\end{array}$ & $\begin{array}{l}51.75^{\mathrm{a}} \\
(31.39- \\
90.03)\end{array}$ & $<0.001$ \\
\hline Actinomycetales & $\begin{array}{c}0.04^{\mathrm{a}} \\
(0.00- \\
0.07)\end{array}$ & $\begin{array}{c}0.04^{\mathrm{a}} \\
(0.02- \\
0.06)\end{array}$ & $\begin{array}{c}0.00^{\mathrm{b}} \\
(0.00- \\
0.01)\end{array}$ & $\begin{array}{c}0.00^{\mathrm{b}} \\
(0.00- \\
0.01)\end{array}$ & $\begin{array}{c}0.03^{\mathrm{a}} \\
(0.01- \\
0.13)\end{array}$ & $\begin{array}{c}0.03^{\mathrm{a}} \\
(0.02- \\
0.16)\end{array}$ & $<0.001$ \\
\hline Actinomycetaceae & $\begin{array}{c}0.03^{\mathrm{a}} \\
(0.00- \\
0.06)\end{array}$ & $\begin{array}{c}0.04^{\mathrm{a}} \\
(0.01- \\
0.06)\end{array}$ & $\begin{array}{c}0.00^{\mathrm{b}} \\
(0.00- \\
0.01)\end{array}$ & $\begin{array}{c}0.00^{\mathrm{b}} \\
(0.00- \\
0.01)\end{array}$ & $\begin{array}{c}0.03^{\mathrm{a}} \\
(0.01- \\
0.13)\end{array}$ & $\begin{array}{c}0.03^{\mathrm{a}} \\
(0.01- \\
0.14)\end{array}$ & $<0.001$ \\
\hline Actinomyces & $\begin{array}{c}0.033^{\mathrm{a}} \\
(0.000- \\
0.060)\end{array}$ & $\begin{array}{c}0.037^{\mathrm{a}} \\
(0.009- \\
0.060)\end{array}$ & $\begin{array}{c}0.001^{\mathrm{b}} \\
(0.000- \\
0.006)\end{array}$ & $\begin{array}{c}0.003^{\mathrm{b}} \\
(0.000- \\
0.006)\end{array}$ & $\begin{array}{c}0.026^{\mathrm{a}} \\
(0.006- \\
0.126)\end{array}$ & $\begin{array}{c}0.034^{\mathrm{a}} \\
(0.014- \\
0.143)\end{array}$ & $<0.001$ \\
\hline Bifidobacteriales & $\begin{array}{c}39.16^{\mathrm{a}} \\
(18.91- \\
46.70)\end{array}$ & $\begin{array}{l}46.10^{\mathrm{a}} \\
(18.05- \\
70.73)\end{array}$ & $\begin{array}{c}0.54^{\mathrm{b}} \\
(0.45- \\
0.65)\end{array}$ & $\begin{array}{c}0.49^{\mathrm{b}} \\
(0.42- \\
0.71)\end{array}$ & $\begin{array}{c}39.16^{c} \\
(10.98- \\
44.47)\end{array}$ & $\begin{array}{l}18.72^{\mathrm{c}} \\
(9.85- \\
64.69)\end{array}$ & $<0.001$ \\
\hline Bifidobacteriaceae & $\begin{array}{c}39.16^{\mathrm{a}} \\
(18.91- \\
46.70)\end{array}$ & $\begin{array}{l}46.10^{\mathrm{a}} \\
(18.05- \\
70.73)\end{array}$ & $\begin{array}{c}0.54^{\mathrm{b}} \\
(0.45- \\
0.65)\end{array}$ & $\begin{array}{c}0.49^{\mathrm{b}} \\
(0.42- \\
0.71)\end{array}$ & $\begin{array}{c}39.16^{\mathrm{c}} \\
(10.98- \\
44.47) \\
\end{array}$ & $\begin{array}{l}18.72^{c} \\
(9.85- \\
64.69)\end{array}$ & $<0.001$ \\
\hline Bifidobacterium & $\begin{array}{l}39.12^{\mathrm{a}} \\
(18.91- \\
46.70)\end{array}$ & $\begin{array}{l}46.08^{\mathrm{a}} \\
(18.01- \\
70.72)\end{array}$ & $\begin{array}{c}0.54^{\mathrm{b}} \\
(0.45- \\
0.65)\end{array}$ & $\begin{array}{c}0.49^{\mathrm{b}} \\
(0.42- \\
0.71)\end{array}$ & $\begin{array}{c}39.12^{c} \\
(10.97- \\
44.46)\end{array}$ & $\begin{array}{l}18.70^{c} \\
(9.82- \\
64.66)\end{array}$ & $<0.001$ \\
\hline Coriobacteriia & $\begin{array}{c}27.29^{\mathrm{a}} \\
(14.31- \\
48.21) \\
\end{array}$ & $\begin{array}{l}21.64^{\mathrm{a}} \\
(13.19- \\
50.92) \\
\end{array}$ & $\begin{array}{c}0.42^{\mathrm{b}} \\
(0.32- \\
0.48)\end{array}$ & $\begin{array}{c}0.40^{\mathrm{b}} \\
(0.26- \\
0.53)\end{array}$ & $\begin{array}{l}34.95^{\mathrm{a}} \\
(5.43- \\
46.25) \\
\end{array}$ & $\begin{array}{l}25.28^{a} \\
(2.33- \\
38.40) \\
\end{array}$ & $<0.001$ \\
\hline Coriobacteriales & $\begin{array}{c}27.29^{\mathrm{a}} \\
(14.31- \\
48.21)\end{array}$ & $\begin{array}{l}21.64^{\mathrm{a}} \\
(13.19- \\
50.92)\end{array}$ & $\begin{array}{c}0.42^{\mathrm{b}} \\
(0.32- \\
0.48)\end{array}$ & $\begin{array}{c}0.40^{\mathrm{b}} \\
(0.26- \\
0.53)\end{array}$ & $\begin{array}{l}34.95^{\mathrm{a}} \\
(5.43- \\
46.25)\end{array}$ & $\begin{array}{l}25.28^{\mathrm{a}} \\
(2.33- \\
38.40)\end{array}$ & $<0.001$ \\
\hline Coriobacteriaceae & $\begin{array}{c}27.29^{\mathrm{a}} \\
(14.31- \\
48.21) \\
\end{array}$ & $\begin{array}{l}21.64^{\mathrm{a}} \\
(13.19- \\
50.92) \\
\end{array}$ & $\begin{array}{c}0.42^{\mathrm{b}} \\
(0.32- \\
0.48)\end{array}$ & $\begin{array}{c}0.40^{\mathrm{b}} \\
(0.26- \\
0.53)\end{array}$ & $\begin{array}{l}34.95^{\mathrm{a}} \\
(5.43- \\
46.25) \\
\end{array}$ & $\begin{array}{l}25.28^{\mathrm{a}} \\
(2.33- \\
38.40) \\
\end{array}$ & $<0.001$ \\
\hline Adlercreutzia & $\begin{array}{c}0.024^{\mathrm{a}} \\
(0.003- \\
0.051)\end{array}$ & $\begin{array}{c}0.014^{\mathrm{a}} \\
(0.006- \\
0.037)\end{array}$ & $\begin{array}{c}0.003^{\mathrm{b}} \\
(0.000- \\
0.003)\end{array}$ & $\begin{array}{c}0.000^{\mathrm{b}} \\
(0.000- \\
0.003)\end{array}$ & $\begin{array}{c}0.059^{\mathrm{c}} \\
(0.006- \\
0.094)\end{array}$ & $\begin{array}{c}0.031^{\mathrm{c}} \\
(0.009- \\
0.217)\end{array}$ & $<0.001$ \\
\hline Collinsella & $\begin{array}{l}9.39^{\mathrm{a}} \\
(1.39- \\
25.36) \\
\end{array}$ & $\begin{array}{l}8.91^{\mathrm{a}} \\
(3.19- \\
21.39) \\
\end{array}$ & $\begin{array}{c}0.21^{\mathrm{b}} \\
(0.17- \\
0.24) \\
\end{array}$ & $\begin{array}{c}0.21^{\mathrm{b}} \\
(0.16- \\
0.25) \\
\end{array}$ & $\begin{array}{l}8.69^{\mathrm{a}} \\
(4.17- \\
33.50) \\
\end{array}$ & $\begin{array}{l}16.18^{\mathrm{a}} \\
(1.88- \\
20.90) \\
\end{array}$ & $<0.001$ \\
\hline Slackia & $\begin{array}{c}0.13^{\mathrm{a}} \\
(0.04- \\
0.21)\end{array}$ & $\begin{array}{l}0.11^{\mathrm{a}} \\
(0.05- \\
0.27)\end{array}$ & $\begin{array}{c}0.01^{\mathrm{b}} \\
(0.00- \\
0.02)\end{array}$ & $\begin{array}{c}0.01^{\mathrm{b}} \\
(0.00- \\
0.01)\end{array}$ & $\begin{array}{c}0.17^{\mathrm{a}} \\
(0.14- \\
0.30)\end{array}$ & $\begin{array}{c}0.19^{\mathrm{a}} \\
(0.01- \\
0.35)\end{array}$ & $<0.001$ \\
\hline Bacteroidetes & $\begin{array}{c}0.54^{\mathrm{a}} \\
(0.11- \\
2.17) \\
\end{array}$ & $\begin{array}{c}0.80^{\mathrm{a}} \\
(0.17- \\
1.67) \\
\end{array}$ & $\begin{array}{c}0.09^{\mathrm{b}} \\
(0.05- \\
0.15) \\
\end{array}$ & $\begin{array}{c}0.10^{\mathrm{b}} \\
(0.05- \\
0.13) \\
\end{array}$ & $\begin{array}{c}3.35^{\mathrm{a}} \\
(0.30- \\
5.91) \\
\end{array}$ & $\begin{array}{c}0.82^{\mathrm{a}} \\
(0.08- \\
6.37) \\
\end{array}$ & $<0.001$ \\
\hline Bacteroidia & $\begin{array}{c}0.54^{\mathrm{a}} \\
(0.11- \\
2.17)\end{array}$ & $\begin{array}{c}0.80^{\mathrm{a}} \\
(0.17- \\
1.67)\end{array}$ & $\begin{array}{c}0.09^{\mathrm{b}} \\
(0.05- \\
0.15)\end{array}$ & $\begin{array}{c}0.10^{\mathrm{b}} \\
(0.05- \\
0.13)\end{array}$ & $\begin{array}{l}3.35^{\mathrm{a}} \\
(0.30- \\
5.91)\end{array}$ & $\begin{array}{c}0.81^{\mathrm{a}} \\
(0.08- \\
6.37)\end{array}$ & $<0.001$ \\
\hline Bacteroidales & $0.54^{\mathrm{a}}$ & $0.80^{\mathrm{a}}$ & $0.09^{\mathrm{b}}$ & $0.10^{\mathrm{b}}$ & $3.35^{\mathrm{a}}$ & $0.81^{\mathrm{a}}$ & $<0.001$ \\
\hline
\end{tabular}




\begin{tabular}{|c|c|c|c|c|c|c|c|c|}
\hline & & $\begin{array}{c}(0.11- \\
2.17)\end{array}$ & $\begin{array}{c}(0.17- \\
1.67)\end{array}$ & $\begin{array}{c}(0.05- \\
0.15)\end{array}$ & $\begin{array}{c}(0.05- \\
0.13)\end{array}$ & $\begin{array}{c}(0.30- \\
5.91)\end{array}$ & $\begin{array}{c}(0.08- \\
6.37)\end{array}$ & \\
\hline 0 & Bacteroidaceae & $\begin{array}{c}0.14^{\mathrm{a}} \\
(0.07- \\
1.67)\end{array}$ & $\begin{array}{c}0.24^{\mathrm{a}} \\
(0.10- \\
1.13)\end{array}$ & $\begin{array}{c}0.07^{\mathrm{b}} \\
(0.04- \\
0.13)\end{array}$ & $\begin{array}{c}0.09^{\mathrm{b}} \\
(0.04- \\
0.11)\end{array}$ & $\begin{array}{c}3.08^{\mathrm{c}} \\
(0.21- \\
5.85)\end{array}$ & $\begin{array}{c}0.53^{\mathrm{c}} \\
(0.07- \\
6.03)\end{array}$ & $<0.001$ \\
\hline - & Bacteroides & $\begin{array}{c}0.14^{\mathrm{a}} \\
(0.07- \\
1.67)\end{array}$ & $\begin{array}{c}0.24^{\mathrm{a}} \\
(0.10- \\
1.13)\end{array}$ & $\begin{array}{c}0.07^{\mathrm{b}} \\
(0.04- \\
0.13)\end{array}$ & $\begin{array}{c}0.09^{\mathrm{b}} \\
(0.04- \\
0.11)\end{array}$ & $\begin{array}{c}3.08^{\mathrm{c}} \\
(0.21- \\
5.85)\end{array}$ & $\begin{array}{c}0.53^{\mathrm{c}} \\
(0.07- \\
6.03)\end{array}$ & $<0.001$ \\
\hline 0 & Porphyromonadaceae & $\begin{array}{c}0.007^{\mathrm{a}} \\
(0.003- \\
0.349)\end{array}$ & $\begin{array}{c}0.013^{\mathrm{a}} \\
(0.006- \\
0.037)\end{array}$ & $\begin{array}{c}0.003^{\mathrm{b}} \\
(0.003- \\
0.011)\end{array}$ & $\begin{array}{c}0.006^{\mathrm{b}} \\
(0.003- \\
0.017)\end{array}$ & $\begin{array}{c}0.071^{\mathrm{c}} \\
(0.014- \\
0.514)\end{array}$ & $\begin{array}{c}0.063^{\mathrm{c}} \\
(0.003- \\
0.631)\end{array}$ & $<0.001$ \\
\hline - & Parabacteroides & $\begin{array}{c}0.007^{\mathrm{a}} \\
(0.003- \\
0.349)\end{array}$ & $\begin{array}{c}0.013^{\mathrm{a}} \\
(0.006- \\
0.037)\end{array}$ & $\begin{array}{c}0.003^{\mathrm{b}} \\
(0.003- \\
0.011)\end{array}$ & $\begin{array}{c}0.006^{\mathrm{b}} \\
(0.003- \\
0.017)\end{array}$ & $\begin{array}{c}0.071^{\mathrm{c}} \\
(0.014- \\
0.514)\end{array}$ & $\begin{array}{c}0.063^{\mathrm{c}} \\
(0.003- \\
0.631)\end{array}$ & $<0.001$ \\
\hline ○ & Prevotellaceae & $\begin{array}{c}0.19^{\mathrm{a}} \\
(0.01- \\
0.63) \\
\end{array}$ & $\begin{array}{c}0.36^{\mathrm{a}} \\
(0.02- \\
0.79) \\
\end{array}$ & $\begin{array}{c}0.009^{\mathrm{b}} \\
(0.003- \\
0.014)\end{array}$ & $\begin{array}{c}0.006^{\mathrm{b}} \\
(0.000- \\
0.011)\end{array}$ & $\begin{array}{c}0.10^{\mathrm{a}} \\
(0.01- \\
0.21) \\
\end{array}$ & $\begin{array}{c}0.14^{\mathrm{a}} \\
(0.01- \\
0.28) \\
\end{array}$ & $<0.001$ \\
\hline - & Prevotella & $\begin{array}{c}0.194^{\mathrm{a}} \\
(0.011- \\
0.634)\end{array}$ & $\begin{array}{c}0.363^{\mathrm{a}} \\
(0.020- \\
0.794)\end{array}$ & $\begin{array}{c}0.009^{\mathrm{b}} \\
(0.003- \\
0.014)\end{array}$ & $\begin{array}{c}0.006^{\mathrm{b}} \\
(0.000- \\
0.011)\end{array}$ & $\begin{array}{c}0.100^{\mathrm{a}} \\
(0.014- \\
0.206)\end{array}$ & $\begin{array}{c}0.137^{\mathrm{a}} \\
(0.006- \\
0.277)\end{array}$ & $<0.001$ \\
\hline & utes & $\begin{array}{c}30.29^{\mathrm{a}} \\
(11.58- \\
65.48)\end{array}$ & $\begin{array}{c}27.64^{a} \\
(10.37- \\
42.67)\end{array}$ & $\begin{array}{l}91.84^{b} \\
(83.66- \\
97.50)\end{array}$ & $\begin{array}{c}90.75^{\mathrm{b}} \\
(74.36- \\
98.31)\end{array}$ & $\begin{array}{c}26.21^{\mathrm{a}} \\
(13.98- \\
55.26)\end{array}$ & $\begin{array}{l}47.08^{a} \\
(8.84- \\
67.65)\end{array}$ & $<0.001$ \\
\hline • & Clostridia & $\begin{array}{l}12.69^{a} \\
(4.63- \\
33.88)\end{array}$ & $\begin{array}{l}18.83^{\mathrm{a}} \\
(6.76- \\
35.33)\end{array}$ & $\begin{array}{c}85.49^{\mathrm{b}} \\
(81.13- \\
95.00)\end{array}$ & $\begin{array}{c}82.78^{\mathrm{b}} \\
(70.84- \\
96.36)\end{array}$ & $\begin{array}{l}15.95^{\mathrm{a}} \\
(7.95- \\
44.59)\end{array}$ & $\begin{array}{l}36.75^{\mathrm{a}} \\
(2.44- \\
45.25)\end{array}$ & $<0.001$ \\
\hline- & Clostridiales & $\begin{array}{l}12.69^{a} \\
(4.63- \\
33.88)\end{array}$ & $\begin{array}{l}18.83^{\mathrm{a}} \\
(6.76- \\
35.33)\end{array}$ & $\begin{array}{c}85.49^{b} \\
(81.13- \\
95.00)\end{array}$ & $\begin{array}{l}82.78^{\mathrm{b}} \\
(70.84- \\
96.36)\end{array}$ & $\begin{array}{l}15.95^{\mathrm{a}} \\
(7.95- \\
44.59)\end{array}$ & $\begin{array}{l}36.75^{\mathrm{a}} \\
(2.44- \\
45.25)\end{array}$ & $<0.001$ \\
\hline$\circ$ & Clostridiales; Other & $\begin{array}{c}0.25^{\mathrm{a}} \\
(0.10- \\
1.14)\end{array}$ & $\begin{array}{c}0.31^{\mathrm{a}} \\
(0.05- \\
0.97)\end{array}$ & $\begin{array}{c}0.06^{\mathrm{b}} \\
(0.03- \\
0.13)\end{array}$ & $\begin{array}{c}0.05^{\mathrm{b}} \\
(0.03- \\
0.13)\end{array}$ & $\begin{array}{c}0.79^{\mathrm{a}} \\
(0.09- \\
2.01) \\
\end{array}$ & $\begin{array}{c}0.54^{\mathrm{a}} \\
(0.01- \\
2.47) \\
\end{array}$ & $<0.001$ \\
\hline - & Other & $\begin{array}{c}0.25^{\mathrm{a}} \\
(0.10- \\
1.14)\end{array}$ & $\begin{array}{c}0.31^{\mathrm{a}} \\
(0.05- \\
0.97)\end{array}$ & $\begin{array}{c}0.06^{\mathrm{b}} \\
(0.03- \\
0.13)\end{array}$ & $\begin{array}{c}0.05^{\mathrm{b}} \\
(0.03- \\
0.13)\end{array}$ & $\begin{array}{c}0.79^{\mathrm{a}} \\
(0.09- \\
2.01)\end{array}$ & $\begin{array}{c}0.54^{\mathrm{a}} \\
(0.01- \\
2.47)\end{array}$ & $<0.001$ \\
\hline$\circ$ & Clostridiaceae & $\begin{array}{c}1.97^{\mathrm{a}} \\
(1.32- \\
6.98)\end{array}$ & $\begin{array}{c}2.28^{\mathrm{a}} \\
(1.56- \\
11.82)\end{array}$ & $\begin{array}{l}82.66^{\mathrm{b}} \\
(78.23- \\
92.91)\end{array}$ & $\begin{array}{l}80.16^{\mathrm{b}} \\
(68.32- \\
94.47)\end{array}$ & $\begin{array}{c}3.56^{\mathrm{a}} \\
(1.23- \\
22.91)\end{array}$ & $\begin{array}{c}5.99^{\mathrm{a}} \\
(1.12- \\
24.29)\end{array}$ & $<0.001$ \\
\hline - & Other & $\begin{array}{c}0.77^{\mathrm{a}} \\
(0.47- \\
2.22)\end{array}$ & $\begin{array}{c}0.75^{\mathrm{a}} \\
(0.47- \\
4.83)\end{array}$ & $\begin{array}{c}66.32^{\mathrm{b}} \\
(60.30- \\
77.61)\end{array}$ & $\begin{array}{l}57.64^{\mathrm{b}} \\
(54.96- \\
72.51)\end{array}$ & $\begin{array}{c}0.67^{\mathrm{a}} \\
(0.48- \\
2.33)\end{array}$ & $\begin{array}{c}0.82^{\mathrm{a}} \\
(0.44- \\
5.27)\end{array}$ & $<0.001$ \\
\hline - & 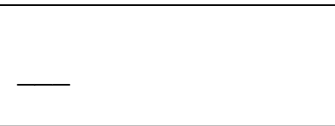 & $\begin{array}{c}0.83^{\mathrm{a}} \\
(0.57- \\
5.43)\end{array}$ & $\begin{array}{c}1.40^{\mathrm{a}} \\
(0.82- \\
10.25)\end{array}$ & $\begin{array}{c}8.52^{\mathrm{b}} \\
(3.79- \\
12.68)\end{array}$ & $\begin{array}{c}7.67^{\mathrm{b}} \\
(3.53- \\
13.62)\end{array}$ & $\begin{array}{c}2.71^{\mathrm{c}} \\
(0.65- \\
18.51)\end{array}$ & $\begin{array}{c}4.76^{\mathrm{c}} \\
(0.47- \\
21.95)\end{array}$ & $<0.001$ \\
\hline - & Clostridium & $\begin{array}{c}0.16^{\mathrm{a}} \\
(0.11- \\
0.25)\end{array}$ & $\begin{array}{c}0.16^{\mathrm{a}} \\
(0.08- \\
0.47)\end{array}$ & $\begin{array}{l}9.97^{\mathrm{b}} \\
(8.78- \\
11.13)\end{array}$ & $\begin{array}{c}9.20^{\mathrm{b}} \\
(7.90- \\
11.19)\end{array}$ & $\begin{array}{c}0.15^{\mathrm{a}} \\
(0.09- \\
1.63)\end{array}$ & $\begin{array}{c}0.19^{\mathrm{a}} \\
(0.11- \\
0.55)\end{array}$ & $<0.001$ \\
\hline - & SMB53 & $\begin{array}{c}0.020^{\mathrm{a}} \\
(0.009- \\
0.151)\end{array}$ & $\begin{array}{c}0.026^{\mathrm{a}} \\
(0.014- \\
0.389)\end{array}$ & $\begin{array}{c}0.011^{\mathrm{b}} \\
(0.009- \\
0.026)\end{array}$ & $\begin{array}{c}0.016^{\mathrm{b}} \\
(0.011- \\
0.077)\end{array}$ & $\begin{array}{c}0.089^{\mathrm{c}} \\
(0.014- \\
0.740)\end{array}$ & $\begin{array}{c}0.197^{\mathrm{c}} \\
(0.009- \\
0.817)\end{array}$ & $<0.001$ \\
\hline 0 & Lachnospiraceae & $\begin{array}{c}6.71^{\mathrm{a}} \\
(1.66- \\
16.53)\end{array}$ & $\begin{array}{c}9.12^{\mathrm{a}} \\
(1.05- \\
14.87)\end{array}$ & $\begin{array}{c}1.40^{\mathrm{b}} \\
(1.14- \\
1.79)\end{array}$ & $\begin{array}{c}1.46^{\mathrm{b}} \\
(1.06- \\
1.74)\end{array}$ & $\begin{array}{c}7.92^{\mathrm{a}} \\
(2.47- \\
16.14)\end{array}$ & $\begin{array}{l}14.56^{\mathrm{a}} \\
(0.75- \\
20.25)\end{array}$ & $<0.001$ \\
\hline - & Other & $0.33^{\mathrm{a}}$ & $0.68^{\mathrm{a}}$ & $0.06^{\mathrm{b}}$ & $0.06^{\mathrm{b}}$ & $0.77^{\mathrm{a}}$ & $0.78^{\mathrm{a}}$ & $<0.001$ \\
\hline
\end{tabular}




\begin{tabular}{|c|c|c|c|c|c|c|c|c|}
\hline & & $\begin{array}{c}(0.05- \\
0.73)\end{array}$ & $\begin{array}{c}(0.07- \\
1.50)\end{array}$ & $\begin{array}{c}(0.04- \\
0.11)\end{array}$ & $\begin{array}{c}(0.03- \\
0.09)\end{array}$ & $\begin{array}{c}(0.27- \\
1.28)\end{array}$ & $\begin{array}{c}(0.05- \\
1.97)\end{array}$ & \\
\hline " & Blautia & $\begin{array}{c}4.75^{\mathrm{a}} \\
(1.16- \\
10.51)\end{array}$ & $\begin{array}{c}6.16^{\mathrm{a}} \\
(0.42- \\
8.29) \\
\end{array}$ & $\begin{array}{c}0.58^{\mathrm{b}} \\
(0.48- \\
0.69)\end{array}$ & $\begin{array}{c}0.60^{\mathrm{b}} \\
(0.46- \\
0.73) \\
\end{array}$ & $\begin{array}{c}4.49^{\mathrm{a}} \\
(1.39- \\
12.61) \\
\end{array}$ & $\begin{array}{l}10.91^{\mathrm{a}} \\
(0.36- \\
14.02)\end{array}$ & 0.002 \\
\hline " & Coprococcus & $\begin{array}{c}0.016^{\mathrm{a}} \\
(0.011- \\
0.066)\end{array}$ & $\begin{array}{c}0.027^{\mathrm{a}} \\
(0.011- \\
0.091)\end{array}$ & $\begin{array}{c}0.014^{\mathrm{b}} \\
(0.009- \\
0.031)\end{array}$ & $\begin{array}{c}0.013^{\mathrm{b}} \\
(0.003- \\
0.023)\end{array}$ & $\begin{array}{c}0.050^{\mathrm{c}} \\
(0.014- \\
0.117)\end{array}$ & $\begin{array}{c}0.086^{\mathrm{c}} \\
(0.000- \\
0.203)\end{array}$ & 0.002 \\
\hline " & Dorea & $\begin{array}{c}0.52^{\mathrm{a}} \\
(0.20- \\
1.40) \\
\end{array}$ & $\begin{array}{c}0.54^{\mathrm{a}} \\
(0.16- \\
0.96) \\
\end{array}$ & $\begin{array}{c}0.35^{\mathrm{a}} \\
(0.30- \\
0.47) \\
\end{array}$ & $\begin{array}{c}0.33^{\mathrm{a}} \\
(0.24- \\
0.44) \\
\end{array}$ & $\begin{array}{c}0.69^{\mathrm{b}} \\
(0.31- \\
1.41) \\
\end{array}$ & $\begin{array}{c}1.01^{\mathrm{b}} \\
(0.18- \\
2.23) \\
\end{array}$ & 0.014 \\
\hline ' & Roseburia & $\begin{array}{c}0.011^{\mathrm{a}} \\
(0.003- \\
0.151)\end{array}$ & $\begin{array}{c}0.013^{\mathrm{a}} \\
(0.003- \\
0.040)\end{array}$ & $\begin{array}{c}0.007^{\mathrm{a}} \\
(0.000- \\
0.020)\end{array}$ & $\begin{array}{c}0.009^{\mathrm{a}} \\
(0.000- \\
0.023)\end{array}$ & $\begin{array}{c}0.031^{\mathrm{b}} \\
(0.026- \\
0.160)\end{array}$ & $\begin{array}{c}0.040^{\mathrm{b}} \\
(0.003- \\
0.280)\end{array}$ & $<0.001$ \\
\hline " & [Ruminococcus] & $\begin{array}{c}0.92^{\mathrm{a}} \\
(0.17- \\
5.49)\end{array}$ & $\begin{array}{c}1.14^{\mathrm{a}} \\
(0.24- \\
3.84)\end{array}$ & $\begin{array}{c}0.25^{\mathrm{b}} \\
(0.20- \\
0.38)\end{array}$ & $\begin{array}{c}0.28^{\mathrm{b}} \\
(0.18- \\
0.35)\end{array}$ & $\begin{array}{c}0.74^{\mathrm{a}} \\
(0.21- \\
1.20)\end{array}$ & $\begin{array}{c}1.19^{\mathrm{a}} \\
(0.11- \\
2.05)\end{array}$ & 0.002 \\
\hline 0 & Peptococcaceae & $\begin{array}{c}0.15^{\mathrm{a}} \\
(0.06- \\
0.40)\end{array}$ & $\begin{array}{c}0.20^{\mathrm{a}} \\
(0.03- \\
0.71)\end{array}$ & $\begin{array}{c}0.06^{\mathrm{b}} \\
(0.02- \\
0.09)\end{array}$ & $\begin{array}{c}0.06^{\mathrm{b}} \\
(0.03- \\
0.09)\end{array}$ & $\begin{array}{c}0.23^{\mathrm{a}} \\
(0.04- \\
1.68)\end{array}$ & $\begin{array}{c}0.34^{\mathrm{a}} \\
(0.01- \\
1.67)\end{array}$ & 0.015 \\
\hline " & Peptococcus & $\begin{array}{c}0.15^{\mathrm{a}} \\
(0.06- \\
0.40)\end{array}$ & $\begin{array}{c}0.20^{\mathrm{a}} \\
(0.03- \\
0.71)\end{array}$ & $\begin{array}{c}0.06^{\mathrm{b}} \\
(0.02- \\
0.09)\end{array}$ & $\begin{array}{c}0.06^{\mathrm{b}} \\
(0.03- \\
0.09)\end{array}$ & $\begin{array}{c}0.23^{\mathrm{a}} \\
(0.04- \\
1.68)\end{array}$ & $\begin{array}{c}0.34^{\mathrm{a}} \\
(0.01- \\
1.67)\end{array}$ & 0.014 \\
\hline 0 & Ruminococcaceae & $\begin{array}{c}1.22^{\mathrm{a}} \\
(0.25- \\
3.55)\end{array}$ & $\begin{array}{c}1.97^{\mathrm{a}} \\
(0.14- \\
9.85)\end{array}$ & $\begin{array}{c}0.25^{\mathrm{b}} \\
(0.18- \\
0.51)\end{array}$ & $\begin{array}{c}0.22^{\mathrm{b}} \\
(0.17- \\
0.38)\end{array}$ & $\begin{array}{c}0.82^{\mathrm{a}} \\
(0.16- \\
4.79)\end{array}$ & $\begin{array}{c}0.58^{\mathrm{a}} \\
(0.11- \\
2.54)\end{array}$ & $<0.001$ \\
\hline " & Faecalibacterium & $\begin{array}{c}0.010^{\mathrm{a}} \\
(0.000- \\
0.146)\end{array}$ & $\begin{array}{c}0.031^{\mathrm{a}} \\
(0.003- \\
0.077)\end{array}$ & $\begin{array}{c}0.003^{\mathrm{b}} \\
(0.000- \\
0.009)\end{array}$ & $\begin{array}{c}0.001^{\mathrm{b}} \\
(0.000- \\
0.011)\end{array}$ & $\begin{array}{c}0.006^{\mathrm{a}} \\
(0.000- \\
0.063)\end{array}$ & $\begin{array}{c}0.011^{\mathrm{a}} \\
(0.000- \\
0.091)\end{array}$ & 0.016 \\
\hline " & Oscillospira & $\begin{array}{c}0.029^{\mathrm{a}} \\
(0.009- \\
0.163)\end{array}$ & $\begin{array}{c}0.033^{\mathrm{a}} \\
(0.011- \\
0.057)\end{array}$ & $\begin{array}{c}0.127^{\mathrm{b}} \\
(0.066- \\
0.320)\end{array}$ & $\begin{array}{c}0.100^{\mathrm{b}} \\
(0.023- \\
0.174)\end{array}$ & $\begin{array}{c}0.083^{b} \\
(0.026- \\
0.434)\end{array}$ & $\begin{array}{c}0.160^{\mathrm{b}} \\
(0.006- \\
0.543)\end{array}$ & $<0.001$ \\
\hline " & Ruminococcus & $\begin{array}{c}0.017^{\mathrm{a}} \\
(0.006- \\
0.031)\end{array}$ & $\begin{array}{c}0.017^{\mathrm{a}} \\
(0.006- \\
0.040)\end{array}$ & $\begin{array}{c}0.009^{\mathrm{b}} \\
(0.006- \\
0.017)\end{array}$ & $\begin{array}{c}0.010^{\mathrm{b}} \\
(0.003- \\
0.014) \\
\end{array}$ & $\begin{array}{c}0.034^{c} \\
(0.011- \\
0.160) \\
\end{array}$ & $\begin{array}{c}0.037^{\mathrm{c}} \\
(0.003- \\
0.054)\end{array}$ & 0.002 \\
\hline 0 & Veillonellaceae & $\begin{array}{c}1.03^{\mathrm{a}} \\
(0.13- \\
4.81)\end{array}$ & $\begin{array}{c}0.97^{\mathrm{a}} \\
(0.54- \\
4.88)\end{array}$ & $\begin{array}{c}0.07^{\mathrm{b}} \\
(0.03- \\
0.12)\end{array}$ & $\begin{array}{c}0.08^{b} \\
(0.03- \\
0.16)\end{array}$ & $\begin{array}{c}0.26^{\mathrm{c}} \\
(0.08- \\
2.63)\end{array}$ & $\begin{array}{c}0.17^{\mathrm{c}} \\
(0.08- \\
3.91)\end{array}$ & $<0.001$ \\
\hline " & Megamonas & $\begin{array}{c}0.11^{\mathrm{a}} \\
(0.01- \\
0.22) \\
\end{array}$ & $\begin{array}{c}0.21^{\mathrm{a}} \\
(0.02- \\
2.38) \\
\end{array}$ & $\begin{array}{c}0.02^{\mathrm{b}} \\
(0.00- \\
0.05) \\
\end{array}$ & $\begin{array}{c}0.02^{\mathrm{b}} \\
(0.01- \\
0.06) \\
\end{array}$ & $\begin{array}{c}0.04^{\mathrm{a}} \\
(0.02- \\
0.35) \\
\end{array}$ & $\begin{array}{c}0.05^{\mathrm{a}} \\
(0.00- \\
0.28) \\
\end{array}$ & 0.009 \\
\hline " & Megasphaera & $\begin{array}{c}0.86^{\mathrm{a}} \\
(0.08- \\
4.68)\end{array}$ & $\begin{array}{c}0.72^{\mathrm{a}} \\
(0.08- \\
2.42)\end{array}$ & $\begin{array}{c}0.04^{\mathrm{b}} \\
(0.02- \\
0.07)\end{array}$ & $\begin{array}{c}0.05^{\mathrm{b}} \\
(0.02- \\
0.08)\end{array}$ & $\begin{array}{c}0.23^{\mathrm{c}} \\
(0.05- \\
2.20)\end{array}$ & $\begin{array}{c}0.09^{\mathrm{c}} \\
(0.04- \\
3.58)\end{array}$ & $<0.001$ \\
\hline " & Phascolarctobacterium & $\begin{array}{c}0.009^{\mathrm{a}} \\
(0.003- \\
0.029) \\
\end{array}$ & $\begin{array}{c}0.009^{\mathrm{a}} \\
(0.000- \\
0.069) \\
\end{array}$ & $\begin{array}{c}0.000^{\mathrm{b}} \\
(0.000- \\
0.006) \\
\end{array}$ & $\begin{array}{c}0.006^{\mathrm{b}} \\
(0.000- \\
0.017)\end{array}$ & $\begin{array}{c}0.011^{\mathrm{a}} \\
(0.003- \\
0.063)\end{array}$ & $\begin{array}{c}0.003^{\mathrm{a}} \\
(0.000- \\
0.046) \\
\end{array}$ & 0.004 \\
\hline • & Erysipelotrichi & $\begin{array}{c}0.81^{\mathrm{a}} \\
(0.21- \\
15.32)\end{array}$ & $\begin{array}{c}1.05^{\mathrm{a}} \\
(0.18- \\
5.59)\end{array}$ & $\begin{array}{c}0.28^{\mathrm{b}} \\
(0.21- \\
0.36)\end{array}$ & $\begin{array}{c}0.30^{\mathrm{b}} \\
(0.22- \\
0.37)\end{array}$ & $\begin{array}{c}0.89^{\mathrm{a}} \\
(0.21- \\
6.46)\end{array}$ & $\begin{array}{c}0.78^{\mathrm{a}} \\
(0.24- \\
12.78)\end{array}$ & 0.008 \\
\hline- & Erysipelotrichiales & $\begin{array}{c}0.81^{\mathrm{a}} \\
(0.21- \\
15.32) \\
\end{array}$ & $\begin{array}{c}1.05^{\mathrm{a}} \\
(0.18- \\
5.59) \\
\end{array}$ & $\begin{array}{c}0.28^{\mathrm{b}} \\
(0.21- \\
0.36) \\
\end{array}$ & $\begin{array}{c}0.30^{\mathrm{b}} \\
(0.22- \\
0.37) \\
\end{array}$ & $\begin{array}{c}0.89^{\mathrm{a}} \\
(0.21- \\
6.46) \\
\end{array}$ & $\begin{array}{c}0.78^{\mathrm{a}} \\
(0.24- \\
12.78) \\
\end{array}$ & 0.005 \\
\hline 0 & Erysipelotrichaceae & $\begin{array}{c}0.81^{\mathrm{a}} \\
(0.21-\end{array}$ & $\begin{array}{c}1.05^{\mathrm{a}} \\
(0.18-\end{array}$ & $\begin{array}{c}0.28^{\mathrm{b}} \\
(0.21-\end{array}$ & $\begin{array}{l}0.30^{\mathrm{b}} \\
(0.22-\end{array}$ & $\begin{array}{c}0.89^{\mathrm{a}} \\
(0.21-\end{array}$ & $\begin{array}{c}0.78^{\mathrm{a}} \\
(0.24-\end{array}$ & 0.006 \\
\hline
\end{tabular}




\begin{tabular}{|c|c|c|c|c|c|c|c|}
\hline & 15.32) & $5.59)$ & $0.36)$ & $0.37)$ & $6.46)$ & $12.78)$ & \\
\hline Bulleidia & $\begin{array}{c}0.019^{\mathrm{a}} \\
(0.006- \\
0.194)\end{array}$ & $\begin{array}{c}0.006^{\mathrm{a}} \\
(0.000- \\
0.123)\end{array}$ & $\begin{array}{c}0.003^{b} \\
(0.000- \\
0.009)\end{array}$ & $\begin{array}{c}0.004^{b} \\
(0.000- \\
0.011)\end{array}$ & $\begin{array}{c}0.016^{\mathrm{a}} \\
(0.000- \\
0.431)\end{array}$ & $\begin{array}{c}0.009^{\mathrm{a}} \\
(0.003- \\
0.014)\end{array}$ & 0.015 \\
\hline [Eubacterium] & $\begin{array}{c}0.26^{\mathrm{a}} \\
(0.08- \\
6.60)\end{array}$ & $\begin{array}{c}0.22^{\mathrm{a}} \\
(0.04- \\
1.17)\end{array}$ & $\begin{array}{c}0.07^{\mathrm{b}} \\
(0.05- \\
0.12)\end{array}$ & $\begin{array}{c}0.08^{\mathrm{b}} \\
(0.03- \\
0.13)\end{array}$ & $\begin{array}{c}0.27^{\mathrm{a}} \\
(0.08- \\
2.94)\end{array}$ & $\begin{array}{c}0.33^{\mathrm{a}} \\
(0.10- \\
6.63)\end{array}$ & $<0.001$ \\
\hline Proteobacteria & $\begin{array}{c}0.39^{\mathrm{a}} \\
(0.24- \\
3.03)\end{array}$ & $\begin{array}{c}0.48^{\mathrm{a}} \\
(0.29- \\
4.74) \\
\end{array}$ & $\begin{array}{c}7.09^{\mathrm{b}} \\
(1.28- \\
15.46)\end{array}$ & $\begin{array}{c}8.34^{b} \\
(0.85- \\
24.53)\end{array}$ & $\begin{array}{c}0.43^{\mathrm{a}} \\
(0.28- \\
0.57)\end{array}$ & $\begin{array}{c}0.43^{\mathrm{a}} \\
(0.21- \\
0.89)\end{array}$ & $<0.001$ \\
\hline Gammaproteobacteria & $\begin{array}{c}0.27^{\mathrm{a}} \\
(0.16- \\
2.98)\end{array}$ & $\begin{array}{l}0.34^{\mathrm{a}} \\
(0.18- \\
4.63)\end{array}$ & $\begin{array}{c}7.04^{\mathrm{b}} \\
(1.23- \\
15.32)\end{array}$ & $\begin{array}{c}8.30^{\mathrm{b}} \\
(0.83- \\
24.39)\end{array}$ & $\begin{array}{c}0.25^{\mathrm{c}} \\
(0.14- \\
0.37)\end{array}$ & $\begin{array}{c}0.31^{\mathrm{c}} \\
(0.18- \\
0.37)\end{array}$ & $<0.001$ \\
\hline Aeromonadales & $\begin{array}{c}0.01^{\mathrm{a}} \\
(0.00- \\
0.07)\end{array}$ & $\begin{array}{c}0.02^{\mathrm{a}} \\
(0.01- \\
0.04) \\
\end{array}$ & $\begin{array}{c}0.03^{\mathrm{b}} \\
(0.02- \\
0.07)\end{array}$ & $\begin{array}{c}0.03^{\mathrm{b}} \\
(0.01- \\
0.05)\end{array}$ & $\begin{array}{c}0.01^{\mathrm{a}} \\
(0.00- \\
0.03)\end{array}$ & $\begin{array}{c}0.01^{\mathrm{a}} \\
(0.01- \\
0.04)\end{array}$ & 0.010 \\
\hline Succinivibrionaceae & $\begin{array}{c}0.009^{\mathrm{a}} \\
(0.003- \\
0.069)\end{array}$ & $\begin{array}{c}0.021^{\mathrm{a}} \\
(0.006- \\
0.043)\end{array}$ & $\begin{array}{c}0.033^{\mathrm{b}} \\
(0.017- \\
0.071)\end{array}$ & $\begin{array}{c}0.030^{\mathrm{b}} \\
(0.014- \\
0.051)\end{array}$ & $\begin{array}{c}0.014^{\mathrm{a}} \\
(0.003- \\
0.029)\end{array}$ & $\begin{array}{c}0.014^{\mathrm{a}} \\
(0.006- \\
0.040)\end{array}$ & 0.013 \\
\hline Anaerobiospirillumi & $\begin{array}{c}0.007^{\mathrm{a}} \\
(0.003- \\
0.060)\end{array}$ & $\begin{array}{c}0.017^{\mathrm{a}} \\
(0.006- \\
0.029)\end{array}$ & $\begin{array}{c}0.031^{\mathrm{b}} \\
(0.017- \\
0.071)\end{array}$ & $\begin{array}{c}0.030^{\mathrm{b}} \\
(0.014- \\
0.051)\end{array}$ & $\begin{array}{c}0.014^{\mathrm{a}} \\
(0.003- \\
0.023)\end{array}$ & $\begin{array}{c}0.011^{\mathrm{a}} \\
(0.006- \\
0.037)\end{array}$ & 0.002 \\
\hline Enterobacteriales & $\begin{array}{c}0.26^{\mathrm{a}} \\
(0.15- \\
2.92)\end{array}$ & $\begin{array}{c}0.32^{\mathrm{a}} \\
(0.14- \\
4.62)\end{array}$ & $\begin{array}{c}6.99^{\mathrm{b}} \\
(1.19- \\
15.30)\end{array}$ & $\begin{array}{c}8.25^{\mathrm{b}} \\
(0.81- \\
24.34)\end{array}$ & $\begin{array}{c}0.23^{\mathrm{c}} \\
(0.13- \\
0.34)\end{array}$ & $\begin{array}{c}0.28^{\mathrm{c}} \\
(0.17- \\
0.33)\end{array}$ & $<0.001$ \\
\hline Enterobacteriaceae & $\begin{array}{c}0.26^{\mathrm{a}} \\
(0.15- \\
2.92)\end{array}$ & $\begin{array}{c}0.32^{\mathrm{a}} \\
(0.14- \\
4.62)\end{array}$ & $\begin{array}{c}6.99^{b} \\
(1.19- \\
15.30)\end{array}$ & $\begin{array}{c}8.25^{\mathrm{b}} \\
(0.81- \\
24.34)\end{array}$ & $\begin{array}{c}0.23^{\mathrm{c}} \\
(0.13- \\
0.34)\end{array}$ & $\begin{array}{c}0.28^{\mathrm{c}} \\
(0.17- \\
0.33)\end{array}$ & $<0.001$ \\
\hline
\end{tabular}

2 


\section{Table 5 (on next page)}

Metabolites of known biological import with profiles that significantly differed over time.

Median (range) peak height of metabolites in feces collected at baseline (days 5-7), at the conclusion of antibiotic administration (days 26-28), and after a 603 day washout (days 631633) from 16 healthy cats, 8 per group, ${ }^{+}$that received $150 \mathrm{mg}$ clindamycin with either a placebo or synbiotic PO once daily for 21 days. ${ }^{+}$Feces from one cat (synbiotic group) unavailable at days 631-633. ${ }^{*}$-values adjusted based on the Benjamini and Hochberg False discovery rate (fdr). Profiles that do not share a common superscript letter differed significantly (fdr-adjusted $P<0.05$ ) based on post-hoc analysis. 


\begin{tabular}{|c|c|c|c|c|c|c|c|}
\hline & \multicolumn{2}{|c|}{ Baseline } & \multicolumn{2}{|c|}{ Days 26-28 } & \multicolumn{2}{|c|}{ Days 631-633 } & \multirow{2}{*}{$\begin{array}{c}\text { Fdr- } \\
\text { adjuste } \\
\text { d P- } \\
\text { value* }\end{array}$} \\
\hline & Placebo & Synbiotic & Placebo & Synbiotic & Placebo & $\begin{array}{c}\text { Synbioti } \\
\mathrm{c}\end{array}$ & \\
\hline \multicolumn{8}{|l|}{ Short chain fatty acid metabolites } \\
\hline 3,4-dihydroxyphenylacetic acid & $\begin{array}{c}589^{\mathrm{a}} \\
(317- \\
1,201)\end{array}$ & $\begin{array}{c}521^{\mathrm{a}} \\
(221- \\
1,577)\end{array}$ & $\begin{array}{l}741^{\mathrm{a}} \\
(263- \\
1,130)\end{array}$ & $\begin{array}{c}594^{\mathrm{a}} \\
(126- \\
1,522) \\
\end{array}$ & $\begin{array}{c}197^{\mathrm{b}} \\
(66- \\
1,436)\end{array}$ & $\begin{array}{c}199^{\mathrm{b}} \\
(63-643)\end{array}$ & $<0.001$ \\
\hline 3-hydroxyphenylacetic acid & $\begin{array}{c}3,350^{\mathrm{a}} \\
(582- \\
12,188)\end{array}$ & $\begin{array}{c}2,860^{\mathrm{a}} \\
(55- \\
11,401)\end{array}$ & $\begin{array}{c}65^{\mathrm{b}} \\
(36-94)\end{array}$ & $\begin{array}{c}57^{\mathrm{b}} \\
(26-239)\end{array}$ & $\begin{array}{c}554^{\mathrm{c}} \\
(77- \\
3,578) \\
\end{array}$ & $\begin{array}{c}275^{\mathrm{c}} \\
(124- \\
758)\end{array}$ & $<0.001$ \\
\hline 4-hydroxyphenylacetic acid & $\begin{array}{c}24,894^{\mathrm{a}} \\
(10,957- \\
34,200)\end{array}$ & $\begin{array}{c}24,248^{\mathrm{a}} \\
(12,980- \\
73,736)\end{array}$ & $\begin{array}{c}693^{\mathrm{b}} \\
(473- \\
6,935)\end{array}$ & $\begin{array}{c}3,268^{b} \\
(378- \\
139,343)\end{array}$ & $\begin{array}{c}48,775^{\mathrm{a}} \\
(10,270- \\
133,645 \\
)\end{array}$ & $\begin{array}{c}47,322^{\mathrm{a}} \\
(837- \\
128,116)\end{array}$ & $<0.001$ \\
\hline 2,3-dihydroxybutanoic acid & $\begin{array}{c}167^{\mathrm{a}} \\
(119-347)\end{array}$ & $\begin{array}{c}193^{\mathrm{a}} \\
(67-240)\end{array}$ & $\begin{array}{c}83^{\mathrm{b}} \\
(18-157)\end{array}$ & $\begin{array}{c}108^{\mathrm{b}} \\
(25-268)\end{array}$ & $\begin{array}{c}216^{\mathrm{a}} \\
(97-356)\end{array}$ & $\begin{array}{c}128^{\mathrm{a}} \\
(63-376)\end{array}$ & $<0.001$ \\
\hline 2-hydroxybutanoic acid & $\begin{array}{c}12,514^{\mathrm{a}} \\
(3,401- \\
161,892)\end{array}$ & $\begin{array}{c}10,110^{\mathrm{a}} \\
(626- \\
61,119)\end{array}$ & $\begin{array}{c}38,839^{\mathrm{b}} \\
(26,636- \\
58,406)\end{array}$ & $\begin{array}{c}38,680^{\mathrm{b}} \\
(18,670- \\
76,553)\end{array}$ & $\begin{array}{c}3,846^{\mathrm{c}} \\
(1,170- \\
13,209)\end{array}$ & $\begin{array}{c}3,082^{\mathrm{c}} \\
(623- \\
13,862)\end{array}$ & $<0.001$ \\
\hline 4-aminobutyric acid & $\begin{array}{c}2,002^{\mathrm{a}} \\
(1,665- \\
12,898)\end{array}$ & $\begin{array}{c}2,573^{\mathrm{a}} \\
(1,189- \\
11,658)\end{array}$ & $\begin{array}{l}112,677^{b} \\
(72,970- \\
190,000)\end{array}$ & $\begin{array}{l}156,808^{b} \\
(56,870- \\
393,600)\end{array}$ & $\begin{array}{l}26,744^{c} \\
(3,966- \\
89,927)\end{array}$ & $\begin{array}{c}20,753^{c} \\
(437- \\
60,568)\end{array}$ & $<0.001$ \\
\hline 2,4-diaminobutyric acid & $\begin{array}{c}1,758^{\mathrm{a}} \\
(568- \\
3,102) \\
\end{array}$ & $\begin{array}{c}1,119^{\mathrm{a}} \\
(184- \\
3,865) \\
\end{array}$ & $\begin{array}{c}210^{\mathrm{b}} \\
(140-350)\end{array}$ & $\begin{array}{c}254^{\mathrm{b}} \\
(109- \\
590) \\
\end{array}$ & $\begin{array}{c}3,095^{\mathrm{c}} \\
(1,652- \\
8,818) \\
\end{array}$ & $\begin{array}{c}3,017^{\mathrm{c}} \\
(765- \\
6,398) \\
\end{array}$ & $<0.001$ \\
\hline 3-phenyllactic acid & $\begin{array}{c}5,539^{a} \\
(781- \\
31,484)\end{array}$ & $\begin{array}{c}5,796^{\mathrm{a}} \\
(438- \\
32,942)\end{array}$ & $\begin{array}{c}9,109^{b} \\
(7,089- \\
11,018)\end{array}$ & $\begin{array}{l}12,813^{\mathrm{b}} \\
(7,617- \\
21,692)\end{array}$ & $\begin{array}{c}6,537^{\mathrm{a}} \\
(1,217- \\
19,572)\end{array}$ & $\begin{array}{c}9,052^{\mathrm{a}} \\
(331- \\
16,813)\end{array}$ & $<0.001$ \\
\hline Lactic acid & $\begin{array}{c}152,579^{\mathrm{a}} \\
(24,216- \\
1,034,220 \\
)\end{array}$ & $\begin{array}{c}120,122^{\mathrm{a}} \\
(10,433- \\
1,403,821 \\
)\end{array}$ & $\begin{array}{c}392,894^{\mathrm{b}} \\
(269,519- \\
1,091,298 \\
)\end{array}$ & $\begin{array}{c}308,949^{\mathrm{b}} \\
(129,795 \\
- \\
638,477)\end{array}$ & $\begin{array}{c}27,338^{c} \\
(11,859- \\
149,087 \\
)\end{array}$ & $\begin{array}{c}35,473^{\mathrm{c}} \\
(6,439- \\
111,809)\end{array}$ & $<0.001$ \\
\hline P-hydroxylphenyl-lactic acid & $\begin{array}{c}3,698^{a} \\
(1,153- \\
6,357) \\
\end{array}$ & $\begin{array}{c}4,503^{\mathrm{a}} \\
(581- \\
12,311) \\
\end{array}$ & $\begin{array}{c}3,590^{\mathrm{a}} \\
(2,472- \\
6,688) \\
\end{array}$ & $\begin{array}{c}4,760^{\mathrm{a}} \\
(2,300- \\
5,993) \\
\end{array}$ & $\begin{array}{l}1,654^{\mathrm{b}} \\
(478- \\
5,019) \\
\end{array}$ & $\begin{array}{l}1,431^{\mathrm{b}} \\
(405- \\
2,022) \\
\end{array}$ & $<0.001$ \\
\hline Propane-1-3-diol & $\begin{array}{c}1,108^{\mathrm{a}} \\
(426- \\
15,239)\end{array}$ & $\begin{array}{c}1,900^{\mathrm{a}} \\
(272- \\
5,779)\end{array}$ & $\begin{array}{l}12,212^{b} \\
(3,684- \\
26,363)\end{array}$ & $\begin{array}{l}12,461^{\mathrm{b}} \\
(4,117- \\
20,201)\end{array}$ & $\begin{array}{c}359^{c} \\
(174- \\
1,203)\end{array}$ & $\begin{array}{c}341^{\mathrm{c}} \\
(99-502)\end{array}$ & $<0.001$ \\
\hline 3,3-hydroxyphenyl propionic acid & $\begin{array}{c}76,962^{\mathrm{a}} \\
(18,783- \\
212,470)\end{array}$ & $\begin{array}{c}45,560^{\mathrm{a}} \\
(865- \\
240,661)\end{array}$ & $\begin{array}{c}789^{\mathrm{b}} \\
(88-1,348)\end{array}$ & $\begin{array}{c}648^{\mathrm{b}} \\
(188- \\
1,431)\end{array}$ & $\begin{array}{c}77,032^{\mathrm{a}} \\
(666- \\
167,768 \\
) \\
\end{array}$ & $\begin{array}{c}27,581^{\mathrm{a}} \\
(140- \\
134,885)\end{array}$ & $<0.001$ \\
\hline $\begin{array}{l}\text { 3-(4-hydroxyphenyl)-propionic } \\
\text { acid }\end{array}$ & $\begin{array}{c}65,664^{\mathrm{a}} \\
(28,474- \\
90,967)\end{array}$ & $\begin{array}{c}56,101^{\mathrm{a}} \\
(4,122- \\
141,022)\end{array}$ & $\begin{array}{c}4,255^{\mathrm{b}} \\
(350- \\
16,751)\end{array}$ & $\begin{array}{c}6,447^{\mathrm{b}} \\
(415- \\
16,156)\end{array}$ & $\begin{array}{l}28,844^{c} \\
(4,747- \\
68,675)\end{array}$ & $\begin{array}{c}14,394^{\mathrm{c}} \\
(12,923- \\
79,425)\end{array}$ & $<0.001$ \\
\hline Pyruvic acid & $\begin{array}{c}7,118^{\mathrm{a}} \\
(1,844- \\
19,684)\end{array}$ & $\begin{array}{c}7,900^{\mathrm{a}} \\
(3,534- \\
12,585)\end{array}$ & $\begin{array}{c}7,744^{\mathrm{a}} \\
(3,418- \\
20,148)\end{array}$ & $\begin{array}{c}9,650^{\mathrm{a}} \\
(1,509- \\
48,246)\end{array}$ & $\begin{array}{c}915^{\mathrm{b}} \\
(456- \\
3,736) \\
\end{array}$ & $\begin{array}{c}1,588^{\mathrm{b}} \\
(489- \\
2,230) \\
\end{array}$ & $<0.001$ \\
\hline
\end{tabular}




\begin{tabular}{|c|c|c|c|c|c|c|c|}
\hline Succinic acid & $\begin{array}{l}236,185^{\mathrm{a}} \\
(14,243- \\
708,079)\end{array}$ & $\begin{array}{c}88,426^{\mathrm{a}} \\
(882- \\
1,122,477 \\
)\end{array}$ & $\begin{array}{c}41,400^{\mathrm{a}} \\
(25,669- \\
96,357)\end{array}$ & $\begin{array}{c}48,077^{\mathrm{a}} \\
(7,555- \\
107,389)\end{array}$ & $\begin{array}{c}8,572^{b} \\
(3,020- \\
65,677)\end{array}$ & $\begin{array}{c}9,082^{b} \\
(1,337- \\
65,270)\end{array}$ & $<0.001$ \\
\hline \multicolumn{8}{|l|}{ Bile acids } \\
\hline Cholic acid & $\begin{array}{c}109,466^{\mathrm{a}} \\
(1,898- \\
200,811)\end{array}$ & $\begin{array}{c}59,483^{\mathrm{a}} \\
(423- \\
220,771)\end{array}$ & $\begin{array}{c}11,303^{b} \\
(113- \\
76,704)\end{array}$ & $\begin{array}{c}27,391^{b} \\
(286- \\
89,000)\end{array}$ & $\begin{array}{c}9,511^{\mathrm{b}} \\
(240- \\
77,925)\end{array}$ & $\begin{array}{c}8,907^{b} \\
(3,191- \\
95,296)\end{array}$ & 0.04 \\
\hline Deoxycholic acid & $\begin{array}{c}3,295^{\mathrm{a}} \\
(77- \\
28,703)\end{array}$ & $\begin{array}{c}1,843^{\mathrm{a}} \\
(109- \\
43,646)\end{array}$ & $\begin{array}{c}136^{\mathrm{b}} \\
(45-5,010)\end{array}$ & $\begin{array}{c}352^{\mathrm{b}} \\
(27- \\
3,531)\end{array}$ & $\begin{array}{c}11,544^{\mathrm{a}} \\
(150- \\
111,319 \\
)\end{array}$ & $\begin{array}{c}8,762^{a} \\
(687- \\
309,022)\end{array}$ & 0.01 \\
\hline \multicolumn{8}{|l|}{ Tryptophan metabolites } \\
\hline Indole-3-acetate & $\begin{array}{l}13,713^{a} \\
(7,780- \\
94,057)\end{array}$ & $\begin{array}{c}8,832^{\mathrm{a}} \\
(3,110- \\
125,618)\end{array}$ & $\begin{array}{l}841^{\mathrm{b}} \\
(541- \\
1,795)\end{array}$ & $\begin{array}{c}1,051^{\mathrm{b}} \\
(448- \\
11,089)\end{array}$ & $\begin{array}{l}15,203^{a} \\
(6,967- \\
22,835)\end{array}$ & $\begin{array}{c}27,026^{\mathrm{c}} \\
(17,204- \\
168,850)\end{array}$ & $<0.001$ \\
\hline Indole-3-lactate & $\begin{array}{c}80,846^{\mathrm{a}} \\
(34,669- \\
127,305)\end{array}$ & $\begin{array}{c}62,189^{\mathrm{a}} \\
(7,536- \\
128,029)\end{array}$ & $\begin{array}{c}6,751^{\mathrm{b}} \\
(2,893- \\
11,123)\end{array}$ & $\begin{array}{c}7,133^{\mathrm{b}} \\
(4,437- \\
22,490)\end{array}$ & $\begin{array}{c}15,933^{\mathrm{b}} \\
(773- \\
44,962)\end{array}$ & $\begin{array}{c}5,311^{\mathrm{b}} \\
(836- \\
54,443)\end{array}$ & $<0.001$ \\
\hline Tryptophan & $\begin{array}{c}190,390^{\mathrm{a}} \\
(132,057- \\
340,750)\end{array}$ & $\begin{array}{c}173,956^{\mathrm{a}} \\
(106,947- \\
276,525)\end{array}$ & $\begin{array}{l}120,418^{\mathrm{b}} \\
(95,182- \\
158,327)\end{array}$ & $\begin{array}{l}153,738^{b} \\
(19,076- \\
294,367)\end{array}$ & $\begin{array}{c}20,219^{c} \\
(3,724- \\
138,699 \\
)\end{array}$ & $\begin{array}{c}35,369^{\mathrm{c}} \\
(5,707- \\
174,485)\end{array}$ & $<0.001$ \\
\hline \multicolumn{8}{|l|}{$\begin{array}{l}\text { Sphingolipid } \\
\text { metabolites }\end{array}$} \\
\hline Cellobiose & $\begin{array}{c}54,905^{\mathrm{a}} \\
(14,235- \\
120,530)\end{array}$ & $\begin{array}{c}92,176^{\mathrm{a}} \\
(5,399- \\
111,969)\end{array}$ & $\begin{array}{c}28,177^{\mathrm{ab}} \\
(6,974- \\
261,178)\end{array}$ & $\begin{array}{l}10,182^{\mathrm{b}} \\
(2,284- \\
14,269)\end{array}$ & $\begin{array}{c}2,513^{\mathrm{b}} \\
(249- \\
26,017)\end{array}$ & $\begin{array}{c}5,248^{\mathrm{b}} \\
(753- \\
24,528)\end{array}$ & $<0.001$ \\
\hline D-erythro-sphingosine & $\begin{array}{c}7,341^{\mathrm{a}} \\
(4,159- \\
39,450)\end{array}$ & $\begin{array}{c}8,433^{a} \\
(2,795- \\
14,346)\end{array}$ & $\begin{array}{l}10,575^{\mathrm{a}} \\
(1,003- \\
22,798)\end{array}$ & $\begin{array}{c}3,460^{\mathrm{a}} \\
(620- \\
20,251)\end{array}$ & $\begin{array}{c}2,778^{\mathrm{b}} \\
(869- \\
6,781)\end{array}$ & $\begin{array}{c}21,981^{\mathrm{a}} \\
(438- \\
49,033)\end{array}$ & $<0.001$ \\
\hline Isopentadecanoic acid & $\begin{array}{l}16,537^{\mathrm{b}} \\
(8,419- \\
47,233)\end{array}$ & $\begin{array}{l}19,852^{\mathrm{a}} \\
(6,576- \\
44,308)\end{array}$ & $\begin{array}{c}32,099^{\mathrm{b}} \\
(1,673- \\
766,411)\end{array}$ & $\begin{array}{c}5,119^{b} \\
(1,627- \\
17,766)\end{array}$ & $\begin{array}{l}25,695^{b} \\
(7,307- \\
84,652)\end{array}$ & $\begin{array}{c}65,848^{c} \\
(21,866- \\
707,919)\end{array}$ & $<0.001$ \\
\hline \multicolumn{8}{|l|}{ Polyamines } \\
\hline Putrescine & $\begin{array}{c}325,567^{\mathrm{a}} \\
(97,835- \\
1,380,413 \\
)\end{array}$ & $\begin{array}{l}129,926^{\mathrm{a}} \\
(44,868- \\
363,883)\end{array}$ & $\begin{array}{c}38,927^{\mathrm{b}} \\
(27,370- \\
102,805)\end{array}$ & $\begin{array}{c}83,581^{\mathrm{a}} \\
(28,669- \\
207,557)\end{array}$ & $\begin{array}{c}60,980^{\mathrm{a}} \\
(11,066- \\
212,790 \\
)\end{array}$ & $\begin{array}{c}201,011^{\mathrm{a}} \\
(6,192- \\
485,041)\end{array}$ & 0.01 \\
\hline \multicolumn{8}{|l|}{ Antioxidants / antimicrobials } \\
\hline 3,4-dihydroxyhydrocinnamic acid & $\begin{array}{c}20,308^{\mathrm{a}} \\
(11,158- \\
79,529)\end{array}$ & $\begin{array}{l}19,951^{\mathrm{a}} \\
(9,793- \\
36,089)\end{array}$ & $\begin{array}{c}6,608^{b} \\
(3,079- \\
14,086)\end{array}$ & $\begin{array}{c}7,699^{b} \\
(4,398- \\
16,818)\end{array}$ & $\begin{array}{l}28,082^{a} \\
(1,849- \\
40,617)\end{array}$ & $\begin{array}{l}26,438^{a} \\
(1,485- \\
61,532)\end{array}$ & $<0.001$ \\
\hline 3,4-dihydroxycinnaminic acid & $\begin{array}{l}4,356^{\mathrm{a}} \\
(1,269- \\
10,007)\end{array}$ & $\begin{array}{c}6,229^{a} \\
(1,990- \\
25,507)\end{array}$ & $\begin{array}{c}2,543^{\mathrm{a}} \\
(1,178- \\
16,989)\end{array}$ & $\begin{array}{c}2,955^{\mathrm{a}} \\
(1,481- \\
18,549)\end{array}$ & $\begin{array}{l}1,468^{\mathrm{b}} \\
(281- \\
6,545)\end{array}$ & $\begin{array}{c}760^{\mathrm{b}} \\
(161- \\
4,120)\end{array}$ & $<0.001$ \\
\hline 3,4-dihydroxybenzoic acid & $\begin{array}{l}4,141^{\mathrm{a}} \\
(1,918- \\
12,984)\end{array}$ & $\begin{array}{l}4,062^{\mathrm{a}} \\
(2,054- \\
13,140)\end{array}$ & $\begin{array}{c}2,114^{\mathrm{b}} \\
(1,533- \\
3,328)\end{array}$ & $\begin{array}{c}2,489^{b} \\
(1,694- \\
4,578)\end{array}$ & $\begin{array}{l}13,395^{\mathrm{c}} \\
(2,783- \\
26,592)\end{array}$ & $\begin{array}{c}6,790^{\mathrm{c}} \\
(518- \\
26,569)\end{array}$ & $<0.001$ \\
\hline
\end{tabular}




\begin{tabular}{|l|c|c|c|c|c|c|c|}
\hline & $6,538^{\mathrm{a}}$ & $11,523^{\mathrm{a}}$ & $1,035^{\mathrm{b}}$ & $1,201^{\mathrm{b}}$ & $16,773^{\mathrm{c}}$ & $16,643^{\mathrm{c}}$ & \\
4-hydroxybenzoate & $(3,972-$ & $(4,231-$ & $(665-$ & $(619-$ & $(8,232-$ & $(420-$ \\
& $27,743)$ & $17,030)$ & $1,411)$ & $1,940)$ & $23,719)$ & $49,060)$
\end{tabular}

2 


\section{Table 6(on next page)}

Metabolic pathways that differed significantly over time.

Pathways that differed significantly over time by group based on fecal metabolite profiles in feces collected at baseline (days 5-7), at the conclusion of antibiotic administration (days 2628), and after a 603 day washout (days 631-633) from 16 healthy cats, 8 per group, + that received $150 \mathrm{mg}$ clindamycin with either a placebo or synbiotic PO once daily for 21 days. +Feces from one cat (synbiotic group) unavailable at the days 631-633 timepoint. Total Cmpds = total compounds in pathway; ${ }^{*}=$ amino acid metabolism, ${ }^{\circ}=$ sugar metabolism,$\dagger$ = short-chain fatty acid metabolism, $\ddagger=$ nucleotide metabolism. 


\begin{tabular}{|c|c|c|c|c|c|}
\hline & & $\begin{array}{c}\text { Total } \\
\text { Cmpds }\end{array}$ & $\begin{array}{c}\text { Hit } \\
\text { s }\end{array}$ & $\begin{array}{c}\text { fdr- } \\
\text { adjusted } \\
\text { P-value }\end{array}$ & $\begin{array}{c}\text { Pathwa } \\
y \\
\text { impact } \\
\text { value }\end{array}$ \\
\hline 1 & Linoleic acid metabolism & 15 & 1 & 0.018 & 0.66 \\
\hline $2 *$ & Alanine, aspartate and glutamate metabolism & 24 & 9 & $1.54 \mathrm{E}-10$ & 0.59 \\
\hline $3^{\circ}$ & Galactose metabolism & 41 & 16 & $2.00 \mathrm{E}-08$ & 0.58 \\
\hline $4^{*}$ & Glycine, serine and threonine metabolism & 48 & 9 & 4.69E-09 & 0.54 \\
\hline $5 *$ & Arginine and proline metabolism & 77 & 16 & $1.54 \mathrm{E}-10$ & 0.48 \\
\hline $6^{*}$ & Taurine and hypotaurine metabolism & 20 & 4 & $1.37 \mathrm{E}-08$ & 0.38 \\
\hline $7^{\circ}$ & Starch and sucrose metabolism & 50 & 8 & $2.87 \mathrm{E}-08$ & 0.36 \\
\hline $8 *$ & beta-Alanine metabolism & 28 & 6 & $7.25 \mathrm{E}-09$ & 0.34 \\
\hline 9 & Pyruvate metabolism & 32 & 2 & $3.82 \mathrm{E}-06$ & 0.32 \\
\hline $10^{*}$ & Phenylalanine metabolism & 45 & 13 & $1.18 \mathrm{E}-08$ & 0.27 \\
\hline $11 \dagger$ & Pantothenate and CoA biosynthesis & 27 & 6 & $2.77 \mathrm{E}-09$ & 0.25 \\
\hline $12 *$ & Cysteine and methionine metabolism & 56 & 8 & $4.43 \mathrm{E}-09$ & 0.23 \\
\hline 13 & Nicotinate and nicotinamide metabolism & 44 & 4 & $1.43 \mathrm{E}-08$ & 0.23 \\
\hline $14^{*}$ & Lysine degradation & 47 & 4 & $1.50 \mathrm{E}-02$ & 0.23 \\
\hline $15+$ & Pyrimidine metabolism & 60 & 9 & $6.20 \mathrm{E}-08$ & 0.22 \\
\hline 16 & Arachidonic acid metabolism & 62 & 1 & $1.01 \mathrm{E}-04$ & 0.22 \\
\hline 17 & Glycerolipid metabolism & 32 & 5 & $2.80 \mathrm{E}-08$ & 0.22 \\
\hline 18 & Histidine metabolism & 44 & 3 & $1.43 \mathrm{E}-08$ & 0.21 \\
\hline $19 *+$ & Amino sugar and nucleotide sugar metabolism & 88 & 9 & $1.37 \mathrm{E}-08$ & 0.21 \\
\hline $20 *$ & Tyrosine metabolism & 76 & 10 & $1.96 \mathrm{E}-09$ & 0.20 \\
\hline
\end{tabular}




\begin{tabular}{|c|c|c|c|c|c|}
\hline 21 & Aminoacyl-tRNA biosynthesis & 75 & 18 & $2.84 \mathrm{E}-10$ & 0.17 \\
\hline $22 \dagger$ & Butanoate metabolism & 40 & 7 & $9.61 \mathrm{E}-11$ & 0.17 \\
\hline $23 *$ & Tryptophan metabolism & 79 & 2 & $2.77 \mathrm{E}-09$ & 0.16 \\
\hline $24 *$ & D-Glutamine and D-glutamate metabolism & 11 & 2 & $3.82 \mathrm{E}-06$ & 0.14 \\
\hline 25 & Inositol phosphate metabolism & 39 & 1 & $2.60 \mathrm{E}-03$ & 0.14 \\
\hline 26 & Citrate cycle (TCA cycle) & 20 & 3 & $9.75 \mathrm{E}-06$ & 0.12 \\
\hline 27 & Sulfur metabolism & 18 & 4 & $1.59 \mathrm{E}-08$ & 0.11 \\
\hline $28^{\circ}$ & Pentose phosphate pathway & 32 & 5 & $8.38 \mathrm{E}-12$ & 0.11 \\
\hline $29 \ddagger$ & Purine metabolism & 92 & 12 & $1.61 \mathrm{E}-10$ & 0.11 \\
\hline $30 *$ & $\begin{array}{l}\text { Phenylalanine, tyrosine and tryptophan } \\
\text { biosynthesis }\end{array}$ & 27 & 5 & 4.90E-09 & 0.11 \\
\hline $31 *$ & Lysine biosynthesis & 32 & 2 & $3.07 \mathrm{E}-03$ & 0.10 \\
\hline 32 & Glycolysis or Gluconeogenesis & 31 & 4 & $2.12 \mathrm{E}-06$ & 0.10 \\
\hline 33 & Sphingolipid metabolism & 25 & 3 & 5.39E-04 & 0.09 \\
\hline $34^{\circ}$ & Pentose and glucuronate interconversions & 53 & 7 & 7.42E-09 & 0.09 \\
\hline 35 & Glycerophospholipid metabolism & 39 & 2 & 3.38E-07 & 0.09 \\
\hline $36 \dagger$ & Propanoate metabolism & 35 & 6 & $2.23 \mathrm{E}-06$ & 0.09 \\
\hline $37^{*}$ & Valine, leucine and isoleucine biosynthesis & 27 & 6 & 9.82E-07 & 0.09 \\
\hline $38^{\circ}$ & Fructose and mannose metabolism & 48 & 3 & 4.94E-04 & 0.07 \\
\hline 39 & Nitrogen metabolism & 39 & 10 & 2.77E-09 & 0.07 \\
\hline $40 *$ & Valine, leucine and isoleucine degradation & 40 & 4 & $1.84 \mathrm{E}-04$ & 0.06 \\
\hline 41 & $\begin{array}{l}\text { Ubiquinone and other terpenoid-quinone } \\
\text { biosynthesis }\end{array}$ & 36 & 4 & $2.84 \mathrm{E}-10$ & 0.05 \\
\hline 42 & Glyoxylate and dicarboxylate metabolism & 50 & 4 & $1.18 \mathrm{E}-06$ & 0.04 \\
\hline 43 & Caffeine metabolism & 21 & 1 & $1.84 \mathrm{E}-04$ & 0.03 \\
\hline
\end{tabular}




\begin{tabular}{|l|l|c|c|c|c|}
\hline 44 & Glutathione metabolism & 38 & 5 & $3.28 \mathrm{E}-10$ & 0.03 \\
\hline 45 & Ascorbate and aldarate metabolism & 45 & 3 & $2.59 \mathrm{E}-08$ & 0.02 \\
\hline 46 & Vitamin B6 metabolism & 32 & 1 & $1.47 \mathrm{E}-05$ & 0.02 \\
\hline 47 & Methane metabolism & 34 & 2 & $1.30 \mathrm{E}-05$ & 0.02 \\
\hline
\end{tabular}

2 